\title{
Los objetos domésticos en la parroquia rural Inmaculada Concepción de La Cañada, Provincia de Maracaibo, Venezuela (1804-1860)
}

\author{
Luis Rincón Rubio* \\ Recibido: 4 de enero de 2020 \\ Dictaminado: 2 de mayo de 2020 \\ Aceptado: 27 de agosto de 2020
}

\section{RESUMEN}

El objetivo de este artículo es estudiar los objetos domésticos como parte significativa de la cultura material en la parroquia rural Inmaculada Concepción de La Cañada, Provincia de Maracaibo, Venezuela, durante el período 1804-1860. Utilizando una metodología que permite sistematizar la información contenida en las fuentes documentales se cuantifica el nivel de bienestar material del que habrían disfrutado los habitantes de la parroquia con base en el tipo y la variedad de objetos presentes en sus viviendas. En consonancia con un reciente "giro material" en las ciencias sociales, se trasciende la concepción funcional de los objetos domésticos como simples útiles o mercancías, abordando su agencia material y explorando cómo dichos objetos pudieron contribuir a producir, reproducir y transformar las relaciones sociales y las prácticas e identidades de los agentes sociales. Las principales fuentes primarias utilizadas consistieron en un conjunto de expedientes de 
inventarios post mortem consultados en el Registro Principal del estado Zulia (Maracaibo, Venezuela).

Palabras clave: Cultura material, objetos domésticos, Inmaculada Concepción de La Cañada, Provincia de Maracaibo, Venezuela, siglo XIX.

\section{Domestic objects in the rural parish Inmaculada Concepción de La Cañada, Province of Maracaibo, Venezuela (1804-1860)}

\section{Abstract}

The objective of this article is to study the domestic objects as a significant part of the material culture in the rural parish La Inmaculada Concepción de La Cañada, Province of Maracaibo (Venezuela), in the years 1804-1860. Using a methodology that allows systematizing the available information, the level of material well-being of the inhabitants of the parish is quantified based on the type and variety of objects present in their homes. In line with a recent "material turn" in the social sciences, the functional concept of domestic objects as simple tools or merchandise is transcended, addressing their material agency and exploring how these objects could have contributed to producing, reproducing and transforming social relationships as well as the practices and identities of the social agents. The main historical sources used were a group of post mortem inventories consulted at the Registro Principal of the Zulia state (Maracaibo, Venezuela).

Key words: material culture, domestic objects, Inmaculada Concepción de La Cañada, Province of Maracaibo, Venezuela, XIX Century.

\section{INTRODUCCIÓN}

$\mathrm{L}$ a cultura material ha sido considerada un elemento importante para comprender las dinámicas sociales y culturales. ${ }^{1}$ Como consecuencia de un reciente "giro material" en las ciencias sociales, se han explorado y teorizado en mayor medida las entidades materiales y se ha apreciado cada vez más el papel que ellas juegan en la constitución de las sociedades, reconociéndose

1 Bauer, Goods, Power, History. Latin America's Material Culture. Braudel, The structures of Everyday Life. Civilization \& Capitalism 15th-18th Century, vol. 1. 
que las identidades y las prácticas de los agentes sociales son constituidas y reconstituidas mediante sus relaciones con el mundo material. ${ }^{2}$

Numerosos para algunas sociedades hispanoamericanas, ${ }^{3}$ son escasos los estudios que abordan las relaciones mutuamente constitutivas entre la cultura material y los agentes sociales en la Venezuela de fines del Antiguo Régimen y principios del período republicano, más allá del rol de las entidades materiales en las dinámicas económicas. ${ }^{4}$ En particular, para la ciudad de Maracaibo, capital de la provincia del mismo nombre, se ha estudiado principalmente la arquitectura de la vivienda doméstica y el equipamiento y servicios urbanos durante el siglo XIX. ${ }^{5}$ Más escasos aún son los estudios que abordan la cultura material en las áreas rurales circunvecinas a la ciudad de Maracaibo. En el marco de proyectos de inventariado del patrimonio cultural, se han identificado las características morfológicas de viviendas con características constructivas del siglo XIX existentes en municipios vecinos a dicha ciudad. ${ }^{6}$ Se han realizado también censos del patrimonio cultural que han registrado objetos considerados de relevancia histórica y se han descrito aspectos funcionales de los mismos, ${ }^{7}$ sin profundizar en las relaciones entre dichos objetos y la creación y reproducción de identidades y prácticas sociales.

En vista de lo anterior, se buscó en este artículo, contribuir al conocimiento de la sociedad y la cultura en la antigua Provincia de Maracaibo a través del estudio de la cultura material en la parroquia rural Inmaculada Concepción de La Cañada (en adelante parroquia La Cañada) durante el período 1804-1860, al nivel de los objetos domésticos. ${ }^{8}$ A partir de este interés, nos preguntamos:

2 Benzecry y Domínguez Rubio, The cultural life of objects. Overholtzer y Robin, "The Materiality of Everyday Life", pp. 1-9.

3 Cf. Moreyra, "La alcoba, el lecho, lo cotidiano. Cultura material de un espacio doméstico. Córdoba (Argentina), siglos XVIII y XIX”, pp. 95-117. Randazzo Ruiz, "La honorabilidad en la apariencia: Teatralidades cotidianas y escenificación de la blancura en el Virreinato de la Nueva Granada (1750-1806)", pp. 427-454.

4 Amodio, "El pan nuestro de cada día. Comercio de harina de trigo y consumo de pan en Caracas durante el siglo XVIII", pp. 83-110. Navarrete, "Torrentes domesticados. La arqueología del agua en la Caracas colonial", pp. 37-58.

5 Pirela Torres, Casas de Maracaibo 1674-1930. Bermúdez Briñez, "Condiciones de vida de una ciudad-puerto del Occidente de Venezuela", pp. 43-59; Vivir en Maracaibo en el siglo $X I X$.

6 Catálogo del Patrimonio Cultural Venezolano. Municipio La Cañada de Urdaneta; Preinventario del patrimonio cultural del estado Zulia - Bienes inmuebles y muebles.

7 Catálogo del Patrimonio Cultural Venezolano 2004-2008. Estado Zulia. Municipio La Cañada de Urdaneta.

8 Estudios recientes han abordado la cultura material en esta parroquia al nivel del paisaje local y de las viviendas domésticas (Rincón Rubio, "El paisaje del parentesco en la parroquia Inmaculada Concepción de La Cañada (Provincia de Maracaibo) a fines del siglo XVII y principios del siglo XIX”, pp. 94-129; "Cultura material y vivienda doméstica en una 
¿Cuáles eran los objetos que existían en las viviendas de la parroquia La Cañada en los años 1804-1860?, ¿cuáles eran los usos y funciones que posibilitaban las características materiales de estos objetos?, ¿cuál era el grado de bienestar material que dichos objetos posibilitaban?, y finalmente, ¿cómo participaban los objetos domésticos en la creación y recreación de las identidades y las prácticas de los agentes sociales en la parroquia en el período en cuestión? Para responder a estas interrogantes se plantea, a manera de hipótesis, que aproximarse a los objetos domésticos como entidades que ejercen agencia material permitirá trascender la concepción funcional de dichos objetos, e identificar más cabalmente la manera en que éstos pudieron contribuir a producir, reproducir y transformar las relaciones sociales y las prácticas e identidades de los agentes sociales.

\section{La Parroquia La Cañada en los años 1804-1860}

La parroquia La Cañada se ubicaba a unos 23 kilómetros al sur de la ciudad de Maracaibo, en la ribera noroccidental del lago del mismo nombre, y abarcaba parte del actual territorio del municipio La Cañada de Urdaneta del Estado Zulia, Venezuela. ${ }^{9}$ El establecimiento de población en el lugar se habría iniciado en las últimas décadas del siglo XVI o primeras décadas del siglo XVII, encontrándose documentada para los años 1637-1644 la colonización estable de la zona. ${ }^{10}$

Rincón Rubio $^{11}$ ha recreado algunos aspectos del contexto social y económico de esta parroquia para el siglo XIX. En el año 1834, la población de la parroquia ascendía a 1822 habitantes repartidos en 238 viviendas. Éstas estaban ubicadas en forma dispersa, tierra adentro y a lo largo de la ribera del Lago de Maracaibo, y estaban construidas en su mayoría con muros de bahareque y techumbre con armadura de vigas o listones de madera cubierta de enea o palmas secas. ${ }^{12}$ Un $43.4 \%$ de los individuos de ambos sexos de ocupación u oficio identificado se dedicaba a actividades asociadas a la crianza de ganado, un $38.1 \%$ a oficios asociados a la navegación y un $10.1 \%$ a actividades asociadas a la extracción y procesamiento de maderas. Los

parroquia rural de la Provincia de Maracaibo en la primera mitad del siglo XIX: La Inmaculada Concepción de La Cañada”, pp. 106-146).

9 Rincón Rubio, "El paisaje del parentesco en la parroquia Inmaculada Concepción de La Cañada...”, pp. 94-129.

10 Rincón Rubio, "Orígenes y consolidación de una parroquia rural en la provincia de Maracaibo: La Inmaculada Concepción de La Cañada, 1688-1834”, pp. 2-55.

11 Rincón Rubio, La Cañada de Urdaneta. Documentos para su historia (1836-1936); La Inmaculada Concepción de La Cañada. Orígenes, estructura familiar y prácticas sociales (1688-1838).

12 Rincón Rubio, “Cultura material y vivienda doméstica en una parroquia rural...”, pp. 106-146. 
productos de la actividad agropecuaria se repartían entre el autoconsumo, el consumo local y la comercialización de ganado en pie y otros productos resultantes de la actividad criadora (carne, lácteos, cueros) con la ciudad de Maracaibo y poblaciones del sur del Lago de Maracaibo. ${ }^{13}$

Durante el período en estudio, la actividad comercial local sería la mínima necesaria para cubrir las necesidades elementales de la población. Para marzo de 1837 existía en la parroquia una única pulpería de tercera clase, dos mesas mixtas y una mesa de venta de licores. ${ }^{14}$ En ese entonces vivían en la parroquia los artesanos que cubrían los servicios más indispensables: nueve carpinteros, cinco zapateros, tres albañiles, dos herreros, un talabartero y un cirujano, además de una lavandera, una teñidora y una comadrona. ${ }^{15}$ La demanda de bienes y servicios que superaran el nivel elemental sería suplida probablemente en los comercios y mercados de la ciudad de Maracaibo. Para el año 1845 se había incrementado significativamente el número de expendios existentes en la parroquia, la cual contaba con una tienda de primera clase y siete tiendas de segunda clase, cantidad que llegaría a 22 negocios de ventorrillos o expendios de víveres en el año $1855 .{ }^{16}$

\section{CONSIDERACIONES TEÓRICAS Y METODOLÓGICAS}

Las entidades materiales son abordadas por la historia, la antropología y otras ciencias sociales bajo el calificativo de "cultura material". En esta investigación se entendió cultura material como "la expresión tangible de la cultura, resultante de las interrelaciones y encuentros permanentes que tienen lugar entre los agentes sociales y las entidades materiales". ${ }^{17}$ Dentro del amplio espectro del entorno material cotidiano se abordó aquí la cultura material al nivel de los objetos domésticos.

A través de su materialidad, los objetos domésticos actúan sobre los agentes sociales, habilitan y contribuyen a constituir ciertas relaciones sociales, prácticas, significados, memorias y formas de clasificar y categorizar el mundo, al mismo tiempo que restringen o limitan otros tipos de interacciones,

13 Rincón Rubio, "La economía en la región histórica zuliana: caso la Cañada de Urdaneta (1834-1926)", pp. 95-137.

14 Ídem. Las pulperías vendían comestibles, loza, quincallas, vinos, bebidas espirituosas y tabaco, mientras que las mesas vendían ropa y comestibles, y en los ventorrillos se podía adquirir productos como granos, papelones, azúcar, bebidas fermentadas, queso, mecates, tejidos de cocuiza y jabón (Cardozo Galué, Maracaibo y su región histórica. El circuito agroexportador 1830-1860).

15 Rincón Rubio, "La economía en la región histórica zuliana: caso la Cañada de Urdaneta (1834-1926)”, pp. 95-137.

16 Ídem.

17 Rincón Rubio, "Cultura material y vivienda doméstica...". 
acciones y/o sentidos. ${ }^{18}$ Sin pretender abogar por ninguna de las teorías que coexisten en la actualidad acerca de la naturaleza de la agencia material de los objetos, ${ }^{19}$ se siguió a Robb ${ }^{20}$ cuando propone que en su diseño los objetos contienen sus propias pistas internas, sus propios "manuales de instrucción" e información de cómo deben ser utilizados, el tipo de respuesta física o psicológica que anticipan, y la forma en que ayudan a canalizar las acciones de los agentes sociales. Así, se consideró que algunos objetos son "fijadores de estándares" que ayudan a tejer la fábrica invisible de lo "normal" y de lo "natural", creando los ambientes y los escenarios apropiados para que se desarrolle la vida cotidiana, y afirmando los estándares y las reglas implícitas en esos ambientes o escenarios. ${ }^{21}$ Otro tipo de objetos domésticos pueden ser considerados como "tecnologías de encantamiento". ${ }^{22}$ Se trata de objetos cuyo diseño incorpora cualidades estéticas o tecnológicas que tienen la intención de evocar un efecto específico sobre los agentes sociales que interactúan con ellos, y que inducen reacciones o respuestas emocionales en estos últimos mediante pistas culturalmente específicas. ${ }^{23}$

Hodder, Studies in Human-Thing Entanglement. Overholtzer y Robin, "The Materiality of Everyday Life", pp. 1-9. Robb, "Beyond Agency", pp. 493-520.

19 La forma en que investigadores de áreas como la historia, la antropología y la arqueología han definido y operacionalizado el concepto de agencia material de los objetos y abordado las complejas dependencias de los seres humanos con los objetos, de los objetos entre ellos, y de los objetos con los seres humanos, varía ampliamente, en direcciones que pueden ser incompatibles entre sí. Así, se ha centrado la atención en aspectos tan diversos como las redes sociales o las redes de discursos sociales y políticos en las que se producen y se ven implicados los objetos; las tecnologías de los materiales con que se construyen los objetos; las características físicas en sí de los objetos; o en el modo en que los objetos activamente le dan forma al mundo en maneras que exceden cualquier intención de los agentes sociales. Para una introducción al tema puede consultarse a Ransom, "Artifacts, others, and temporality: an enactive and phenomenological approach to material agency". Hodder, Studies in HumanThing Entanglement. Overholtzer y Robin, "The Materiality of Everyday Life", pp. 1-9. Robb, "What Do Things Want?...", pp. 166-180.

21 Ídem. Los objetos fijadores de estándares son objetos de bajo perfil, que reproducen estándares y significados ampliamente compartidos, que afirman normas básicas de orden y comportamiento, creando una reacción de conformidad o de aceptación inconsciente, y que reafirman que los agentes sociales que los usan se ajustan a unos estándares compartidos de conocimiento y comportamiento (Robb. "What Do Things Want?...", pp. 166-180).

22 Robb, "What Do Things Want?...", pp. 166-180.

23 Ejemplo de estas pistas lo sería, por ejemplo, la decoración de la proa de las canoas tradicionales utilizadas por los isleños trobriandeses de Papúa Nueva Guinea en sus expediciones comerciales (Robb, "What Do Things Want?..., pp. 166-180. Gell, Art and Agency. An Anthropological Theory). Los elaborados diseños en las proas de estas canoas incorporaban la intención de crear temor y confusión en los socios comerciales de los trobriandeses a medida que éstos se les aproximaban para realizar actividades de intercambio comercial/ceremonial, dándole así una ventaja a los trobriandeses en los intercambios comerciales que tenían luego lugar (Gell, Art and Agency. An Anthropological Theory). 
Desde el punto de vista de su agencia material, otros objetos pueden ser considerados como "objetos irresistibles", como una subcategoría de las tecnologías de encantamiento. ${ }^{24}$ Se trata de objetos intrínsecamente deseables que son a menudo "símbolos clave" o distintivos de éxito o de preeminencia social, y que no pueden ser cuestionados a lo interno de una cultura, dado que ello equivaldría a cuestionar los valores esenciales de dicha cultura. ${ }^{25}$ Desde el punto de vista estético se trata de objetos que permiten una evaluación de valor relativamente simple, de forma tal que puedan ser fácilmente clasificados en forma jerárquica de acuerdo a criterios obvios, como su costo o su brillantez visual. Desde el punto de vista de su agencia material, los objetos fijadores de estándares tendrán un menor valor simbólico que las tecnologías de encantamiento y los objetos irresistibles, los cuales, como hemos visto, incorporan calidades de diseño que tienen la intención de evocar un efecto específico sobre los agentes sociales que interactúan con ellos.

Para abordar la cultura material al nivel de los objetos domésticos que existían en las viviendas de la parroquia La Cañada en el período estudiado se clasificaron, en primer lugar, dichos objetos en cinco categorías, según los usos y funciones que habrían posibilitado sus características materiales: objetos de primera necesidad, de trabajo, de confort, de refinamiento y suntuarios. Con el fin de caracterizar cuantitativamente el grado de bienestar material que posibilitaban los objetos mencionados y facilitar las comparaciones entre los diferentes casos, se calculó un Índice de Nivel de Vida (INV), con base en el tipo y la variedad de objetos presentes en las viviendas. ${ }^{26}$ Para construir este indicador se utilizaron 62 criterios, agrupados en las categorías antes mencionadas (Tabla 1). ${ }^{27}$ Los criterios para la construcción del INV fueron

Las reacciones o respuestas anticipadas inducidas por las tecnologías de encantamiento no son universales; se trata de reacciones o respuestas convencionalizadas y dependientes de un conocimiento cultural específico. En sociedades jerarquizadas los objetos que son tecnologías de encantamiento a menudo materializan afirmaciones sobre superioridad social, incorporando características de diseño como un costo elevado o materiales de disponibilidad limitada (Robb, "What Do Things Want?...", pp. 166-180).

24 Robb, "What Do Things Want?...", pp. 166-180.

25 Para poder evocar esta reacción en quien interacciona con ellos, los objetos irresistibles deben incorporar tres características principales en su diseño. En primer lugar, deben ser objetos que puedan ser exhibidos; en segundo lugar, deben evocar los valores del grupo a través de sus materiales de elaboración, de su confección, o de su simbolismo, y en tercer lugar, deben permitir o provocar que se puedan evaluar o calificar las demandas o pretensiones de superioridad que su uso plantea (Robb, "What Do Things Want?...", pp. 166-180).

26 Baulant, Micheline, "L'áppréciation du niveau de vie. Un problème, une solution", pp. 267302; "Ascétique ou douillette ? L'existence des ecclésiastiques de Brie aux XVIIe et XVIIIe siècles”, pp. 475-486.

27 Para calcular el INV se asignó un valor de 1 a cada criterio si éste estaba presente en la vivienda doméstica, o un valor de 0 si estaba ausente, y se totalizó el número de criterios 
escogidos con base en la frecuencia de aparición de los objetos en los inventarios post mortem que constituyeron la fuente documental principal de la investigación. Siguiendo a Baulant ${ }^{28}$ y a Bouchard, ${ }^{29}$ se excluyeron del INV los objetos de trabajo, por considerar que su presencia es indicativa de la ocupación o actividad económica principal desarrollada por el jefe de familia, más que del nivel de bienestar material del que disfrutaba la misma.

Desde el punto de vista de su agencia material, los objetos de primera necesidad, de trabajo y de confort fueron considerados como objetos "fijadores de estándares". Por otro lado, los objetos de refinamiento fueron considerados como "tecnologías de encantamiento", mientras que los objetos suntuarios, como por ejemplo las joyas personales que portaban los agentes sociales, fueron considerados como "objetos irresistibles".

Las principales fuentes primarias utilizadas en la investigación fueron un conjunto de 16 expedientes de inventarios y particiones de bienes de los años 1804-1860 ubicados en el Registro Principal del Estado Zulia (Maracaibo, Venezuela); tales documentos constituyen la totalidad de los expedientes conservados para dicho período de tiempo, realizados tras la defunción de individuos que poseían una vivienda en la parroquia La Cañada. ${ }^{30}$ En diez de estos casos los individuos en cuestión poseían su vivienda o hato tierra adentro en la parroquia, ${ }^{31}$ mientras que en los seis casos restantes se trataba de

presentes dentro de cada serie o categoría. El INV será entonces indicativo de la variedad de objetos domésticos de las diferentes categorías que existían en las viviendas, y no de la cantidad o del valor de dichos objetos. Se calculó el INV sobre una base de 100, asignando un peso de $10 \%$ a la categoría de objetos de primera necesidad y de $30 \%$ a cada una de las categorías de confort, refinamiento y objetos suntuarios, y sumando los subtotales ponderados de las cuatro categorías. Así, la categoría de objetos de primera necesidad, que se supone deberían estar presentes en todas las viviendas de la parroquia al ser los más esenciales para desarrollar las funciones básicas de la vida cotidiana, tendrá un peso menor en el valor del INV, mientras que las categorías de confort, refinamiento y objetos suntuarios, que representan objetos relativamente superfluos y que deberían ser por ello más representativos de niveles diferenciados de bienestar material, tendrán cada una de ellas igual peso y representarán en forma conjunta un $90 \%$ del valor del INV.

28 Baulant, “Ascétique ou douillette... ", pp. 475-486.

29 Bouchard, "La culture matérielle des canadiens au XVIIIe siècle : analyse du niveau de vie des artisans du fer", pp. 479-498.

30 La sección "Civiles" del Registro Principal del Estado Zulia, en la cual se conservaban los expedientes de inventarios y particiones utilizados en este estudio al momento de su consulta, fue trasladada por las autoridades competentes en fecha posterior al Acervo Histórico del Estado Zulia, Maracaibo, Venezuela.

31 Archivo del Registro Principal del estado Zulia (en adelante ARPEZ). Civiles. C-2-14 [1804], fol. $\mathrm{s} / \mathrm{n}$, Inventario avalúos, división y partición de los bienes de Doña Petronila Urdaneta. C-12-9 [1820], fol. 8-24v, Mortuoria de don José Manuel Rincón. C-37-10 [1827-1828], fol. 17-19, Mortuoria de don Manuel Gutiérrez. C-37-12 [1828-1829], fol. 1-31v, Mortuoria de don Salvador Conil. C-39-1 [1829-1830], fol. 21-22, Mortuoria de José María Rincón. 
Tabla 1

Criterios que componen el Índice de Nivel de Vida (INV)

\begin{tabular}{ll}
\hline Primera necesidad & Confort \\
\hline
\end{tabular}

Útiles de cocina y para consumo de alimentos

- Recipiente(s) de cobre o de hierro destinado(s) a la cocción de alimentos (calderos, pailas)

- Útiles para otro modo de cocción de alimentos (parrilla, asador, sartén)

- Piedra de moler maíz y/o piedra de moler pan, pilón de amasar

- Piedra de moler cacao o chocolate

- Otros objetos de cocina (almirez, rallo)

- Mesa para salar

- Recipientes para contener alimentos (cántaras, tinajas, jarras)

- Vajilla básica (platos, vasos, pocillos, escudillas comunes)

Descanso

- Catre o cama de viento de lienzo

- Catre(s) de viento de cuero

- Ropa de cama

- Mesa

- Taburetes, sillas y/o banquetas

Gestión

- Baúl o caja

- Estante/despensa

- Otro (estante pequeño, baulito, cajitas)

Vestimenta básica

- Ropa de paño ordinario (casaca, calzones)
Mobiliario

- Sillones, butacas, sillas de brazos

- Muebles de cedro o caoba (mesa, cama, rinconeras)

- Otros muebles (escaparate, cómoda, estante con cornisa, caja de género, biombo, perchero, sillas extranjeras, escritorio)

Iluminación

- Farol y/o fanal

- Bombas, ventosas y/o cornucopia de vidrio

- Candelero de cobre o de metal

Otros Objetos

- Cafetera y/o molino de café

- Aguador

- Plancha

- Batea de lavar, ponchera

- Quitasol o paraguas

- Otros (ropa fina de cama, fundas, ponchera, botija vidriada)

C-105-9 [1838], fol. 1-4v, Mortuoria de María del Carmen Negrón. C-123-2 [1840], fol. 6v-8v, Mortuoria de Feliciano Rincón. C-132-15 [1841], fol. 10v-12v, Inventario y avalúo de los bienes que quedaron por fallecimiento de la Sra. María Rafaela Fereyra. C-197-10 [1848], fol. 1v-4, Testamentaria de Lázaro Boscán. C-206-6 [1850], fol. 1v-7v, Testamentaria de Camilo Rincón. Por "hato" se entendía y se entiende en el lugar una hacienda de campo destinada a la cría de ganado mayor y menor. 
Continuación Tabla 1

\begin{tabular}{|c|c|}
\hline Primera necesidad & Confort \\
\hline Refinamiento & Objetos suntuarios \\
\hline $\begin{array}{l}\text { Decoración } \\
\text { - Cuadros y/o esculturas de tema religioso } \\
\text { Lectura } \\
\text { - Libros de temas religiosos, tratados } \\
\text { de moral, otros temas (leyes, política, } \\
\text { castellano, historia, geografía) } \\
\text { Objetos de mesa } \\
\text { - Cubiertos de plata } \\
\text { - Jarras, vasos, copas de cristal } \\
\text { - Soperas, platones, platos finos } \\
\text { - Vestimenta no básica } \\
\text { - Ropa masculina o femenina de paño, } \\
\text { lana y/o seda, pañuelo, sombrero }\end{array}$ & $\begin{array}{l}\text { Objetos de lujo } \\
\text { - } \text { Caleta } \\
\text { - } \text { Bastón engastado en metal, oro o } \\
\text { - } \text { Rosario de oro y/o perlas } \\
\text { - Peinillas, peinetas de carey } \\
\text { - Tercerola/fusil fino, pistola } \\
\text { - } \text { guarnición de plata } \\
\text { - Freno, espada, daga guarnecidos } \\
\text { - Silla de montar forrada en } \\
\text { - } \text { terciopelo } \\
\text { - Otros objetos de oro o plata } \\
\text { (mondadientes, palangana, platillos, } \\
\text { baulito, campanilla) }\end{array}$ \\
\hline $\begin{array}{l}\text { Higiene } \\
\text { - } \quad \text { Navajas de afeitar, espejo, tijeras } \\
\text { finas y/o bacinilla o ponchera de afeitar } \\
\text { - Caja o vaso excretorio, bacín, y/o } \\
\text { escupidera, visitadora (enema), ventosa } \\
\text { - } \text { Aguaducho/aguamanil } \\
\text { - Lebrillo de madera o vidriado } \\
\text { - Tina o batea de baño } \\
\text { Otros objetos de refinamiento } \\
\text { - Reloj de sol } \\
\text { - Reloj de faltriquera } \\
\text { - Caja habanera } \\
\text { - } \quad \text { Tinstrumento musical (guitarra, arpa) } \\
\text { de paper } \\
\text { - Otros (espejo, espejuelos, anteojo de } \\
\text { larga vista, percha, botiquín, escaño, } \\
\text { etcétera) }\end{array}$ & $\begin{array}{l}\text { Joyas } \\
\text { - Zarcillos/orejeras/aros, peinetas/ } \\
\text { peinillas engastadas en oro o plata } \\
\text { - Cadenas/gargantillas, mancorna de } \\
\text { cuello, medallas/cruces de oro } \\
\text { - Mancornas/botones de oro y/o } \\
\text { piedras preciosas } \\
\text { - Reloj/cadena de reloj de oro } \\
\text { - Sortijas de oro y/o piedras preciosas } \\
\text { - Prendedores, alfileres de oro o plata } \\
\text { y/o piedras preciosas, cinturones con } \\
\text { hebillas de oro o plata } \\
\text { - Hebillas, charreteras de pies, de oro } \\
\text { o plata }\end{array}$ \\
\hline
\end{tabular}

Fuente: Elaboración propia. 
viviendas ubicadas en las riberas del lago de Maracaibo (hatos playeros). ${ }^{32} \mathrm{La}$ riqueza patrimonial de estos individuos al momento de su defunción variaba entre 5468 y 97789 reales; dado este amplio rango de riqueza patrimonial, el cuerpo documental se considera representativo de las familias de la parroquia que poseían algún bien de fortuna.

El estudio de la cultura material al nivel de los objetos domésticos en una sociedad del pasado a partir de escrituras de inventarios post mortem presenta numerosos obstáculos, relacionados con la representatividad, la calidad y el grado de información en ellos presente. ${ }^{33}$ Por ello, más que formular aseveraciones concluyentes, en esta investigación se proponen interpretaciones a modo de hipótesis, que deberán ser verificadas a medida que surja más información sobre la cultura material de la sociedad en cuestión.

\section{LOS ObJETOS DOMÉSTICOS EN LAS VIVIENDAS DE LA PARROQUIA LA CAÑADA}

En la Figura 1 se ilustra la cantidad de objetos domésticos que existían en las viviendas de la parroquia representadas en el corpus documental, mientras que en la Tabla 2 se presenta la proporción media de objetos y los valores totales promedio de los objetos por categoría. ${ }^{34}$ La cantidad de objetos en las diferentes viviendas variaba ampliamente. Los objetos domésticos relacionados con las necesidades básicas del ser humano y actividades para la obtención del sustento diario eran en promedio los más numerosos. En las viviendas existían, en promedio, unos 21 objetos de primera necesidad y unos 33 de trabajo, los cuales representaban en conjunto un $72.5 \%$ del total de los objetos. Dado que las viviendas o hatos de la parroquia La Cañada eran en general unidades

32 ARPEZ. Civiles. C-44-2 [1830-1832], fol. 15-28v, Mortuoria del presbítero José Vicente Rodríguez. C-86-2 [1832], fol. 7-10v, 25-27, Mortuoria de Francisco Antonio Urdaneta. C-206-18 [1851], fol. s/n, Diligencias de nombramiento de curador y tutor de los menores hijos de Agustín Paz ya difunto. C-255-2 [1846], fol. 15-17v, 58v, Mortuoria de Tomás Vega. C-255-16 [1857], fol. 3v-5v, Causa mortuoria del finado Bernardo González. C-255-5 [1860], fol. s/n, Mortuoria de José Manuel Atencio.

33 Cf. Almenar Fernández, "Los inventarios post mortem de la Valencia medieval. Una fuente para el estudio del consumo doméstico y los niveles de vida”, pp. 533-566. Sobrado Correa, "Los inventarios post-mortem como fuente privilegiada para el estudio de la historia de la cultura material en la edad moderna", pp. 825-861.

34 Los objetos listados en los inventarios por pares o por medidas de cantidad como docenas, o en cantidades no claras, fueron considerados como un solo objeto. Por ejemplo, "un par de estribos" se consideró como un único objeto, así como también, por ejemplo, "una docena y media de cueros", "unas arganas nuevas", "un juego de hierro de colchar con sus tablas y piña", "unas argollas de hierro viejas", "dos cargas de bejuco", "una navaja de ocho piezas", "una escribanía compuesta de cuatro piezas". 


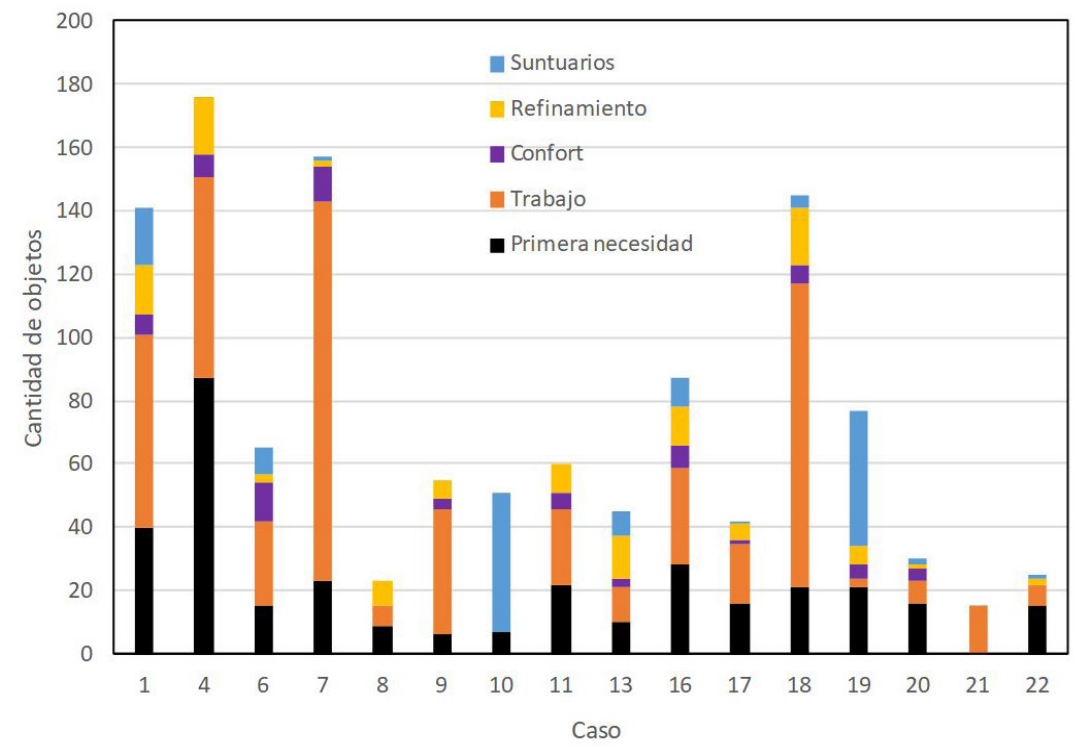

Figura 1. Cantidad de objetos domésticos en viviendas de la parroquia La Cañada (1804-1860).

Fuente: ARPEZ. Civiles. C-2-14 (caso 1). C-12-9 (caso 4). C-37-10 (caso 6). C-39-1 (caso 7). C-44-2 (caso 8). C-86-2 (caso 9). C-105-9 (caso 10). C-123-2 (caso 11). C-132-15 (caso 13). C-197-10 (caso 16). C-206-6 (caso 17). C-255-2 (caso 18). C-255-16 (caso 19). C-255-5 (caso 20). C-37-12 (caso 21). C-206-18 (caso 22). Se utilizan las mismas fuentes en las Tablas 2 y 3 .

productivas dedicadas a la crianza del ganado mayor y menor o a actividades como la pesca y la navegación, no extraña que los objetos de trabajo fuesen los más abundantes. ${ }^{35}$

35 En los hatos ubicados tierra adentro, los cuales eran por lo general unidades productivas dedicadas a la crianza de ganado mayor y menor, los objetos de trabajo incluían utensilios utilizados en la ganadería, como por ejemplo títulos de hierro y señal, romanas, sogas, jeringas de cobre, tarros de ordeñar, aperos de burro y sillas de montar; utensilios para la elaboración de queso y mantequilla como bateas y vasijas de leche; objetos utilizados en el trabajo de campo como hachas, serruchos, machetes y azadones; y armas como pistolas y escopetas. En los hatos ubicados en la ribera lacustre podían desarrollarse tanto actividades de crianza de ganado como actividades de navegación en el Lago de Maracaibo. Así, se encontraban en las viviendas de estos hatos playeros utensilios de trabajo como los ya mencionados para los hatos ubicados tierra adentro, así como también objetos relacionados con la navegación, 
Tabla 2

Proporción y valor de objetos domésticos en viviendas de la parroquia La Cañada (1804-1860)

\begin{tabular}{lrrrrr}
\hline Categoría de objetos & $\begin{array}{c}\text { Proporción } \\
\text { media de } \\
\text { objetos (\%) }\end{array}$ & $\begin{array}{c}\text { Valor medio } \\
\text { (reales) }\end{array}$ & $\begin{array}{c}\text { Valor medio } \\
\text { por objeto } \\
\text { (reales) }\end{array}$ & $\begin{array}{c}\text { Valor } \\
\text { proporcional de } \\
\text { la categoría* }\end{array}$ & $\begin{array}{c}\text { Indice } \\
\text { relativo de } \\
\text { valor** }\end{array}$ \\
\hline Primera necesidad & 28.0 & 166.0 & 7.9 & 17.5 & 0.6 \\
Trabajo & 44.5 & 240.9 & 7.3 & 25.3 & 0.6 \\
Confort & 5.8 & 68.4 & 15.9 & 7.2 & 1.2 \\
Refinamiento & 10.0 & 69.4 & 9.3 & 7.3 & 0.7 \\
Suntuarios & 11.7 & 405.9 & 46.7 & 42.7 & 3.7 \\
Total & 100.0 & 950.6 & & 100.0 & \\
\hline
\end{tabular}

*Valor medio de los objetos en la categoría/Valor medio de todos los objetos en la unidad doméstica)x100.

**Valor proporcional de objetos en la categoría/Proporción de objetos en la categoría.

Por otra parte, existían en las viviendas de la parroquia unos 21 objetos que pudieran considerarse superfluos en menor o mayor grado (en promedio cuatro objetos de confort, 7.5 de refinamiento y nueve suntuarios), los cuales representaban un $27.5 \%$ del total de objetos. Como se ha indicado, para mediados del siglo xIx la base artesanal o manufacturera en la parroquia La Cañada era escasa. Aunque algunos de los objetos domésticos existentes en las viviendas, como por ejemplo algunos de los objetos de trabajo o de primera necesidad, pudieron haber sido elaborados por los artesanos locales, es de pensar que una buena parte de ellos hayan sido de elaboración foránea, y que hayan sido adquiridos por sus propietarios en los pocos comercios de la parroquia o en los comercios y mercados de la ciudad de Maracaibo. Este último pudo ser el caso de muchos de los objetos de confort, de refinamiento y suntuarios.

como por ejemplo piraguas y planos de navegación, canoas, hierros para el calafateo de embarcaciones y utensilios de pesca. Tanto en los hatos ubicados tierra adentro como en los hatos playeros se podían encontrar ocasionalmente utensilios o herramientas diversas, como por ejemplo martillos y tijeras de zapatería, cucharas de albañilería y martillos de carpintería, indicativos de tareas domésticas que pudieron haber cubierto necesidades de los integrantes de la unidad doméstica, o de actividades productivas secundarias que pudieron haber complementado la actividad productiva principal de la unidad doméstica. 
El valor total de los objetos domésticos por vivienda variaba también ampliamente, con un mínimo de 160 reales $^{36}$ y un máximo de 3954 reales ${ }^{37}$ Los objetos de primera necesidad y de trabajo representaban en promedio un $42.8 \%$ del valor total de los objetos domésticos, y eran los de menor valor medio. Recordemos que estos objetos constituían en conjunto un $72.5 \%$ de los objetos existentes en las viviendas, lo cual resulta en un índice relativo de valor de alrededor de 0.6 para estas dos categorías en conjunto, inferior a la unidad; ello indica que las familias de la parroquia concentraban una proporción relativamente baja de su patrimonio en dichos tipos de objetos. ${ }^{38}$

Por otro lado, los objetos de confort, de refinamiento y suntuarios, que constituían un $27.5 \%$ de los objetos existentes en las viviendas, representaban en conjunto el restante $57.2 \%$ del valor total promedio de los objetos domésticos, lo cual resulta en un índice relativo de valor de 2.1 para estas tres categorías en conjunto. Ello indicaría que las familias de la parroquia La Cañada que poseían algún bien de fortuna concentraban una elevada proporción de su patrimonio en la adquisición de objetos que podrían considerarse relativamente superfluos. En particular, es de destacar el elevado índice relativo de valor de 3.7 correspondiente a los objetos suntuarios, el más elevado de todas las categorías, lo cual indicaría que dichas familias concentraban una proporción muy elevada de su patrimonio en adquirir objetos de lujo y joyas. Los objetos suntuarios eran los más valiosos, con un valor promedio individual de alrededor de 47 reales, seguidos por los objetos de confort con un valor promedio de unos 16 reales por objeto.

En la Tabla 3 se muestran los valores del INV para las diferentes familias representadas en el corpus documental, con base en los objetos existentes en sus viviendas. El nivel de bienestar material de estas familias habría sido en general bastante bajo, con un INV promedio de sólo 18.5, y habría variado ampliamente, con un valor máximo de 40.9 que no llegaba a la mitad del valor teórico máximo de 100.

Todos los componentes del INV presentan valores medios muy bajos, lo cual refleja la poca variedad de objetos de las diferentes categorías que habrían existido en las viviendas de la parroquia. Los objetos más variados eran los de primera necesidad, que alcanzan en promedio un 37\% del valor teórico máximo para la categoría. Por otro lado, los objetos menos variados eran los de refinamiento, que representan sólo un 14.7\% del valor teórico máximo de

\footnotetext{
ARPEZ. Civiles. C-44-2 [1830-1832].

ARPEZ. Civiles. C-255-16 [1857].

Un índice relativo de valor igual a 1 indica que el valor proporcional de los objetos dentro de la categoría en cuestión era igual a la cantidad relativa de dichos objetos en la vivienda; los valores inferiores a 1 indican que el valor proporcional de los objetos dentro de la categoría era inferior a la cantidad relativa de dichos objetos (es decir, las familias concentraban una
} 
esta categoría. Los objetos suntuarios y de confort tampoco eran muy variados, al alcanzar en promedio sólo un $16.3 \%$ y un $18.3 \%$ respectivamente de los valores teóricos máximos de las categorías. Lo anterior indica que aunque las familias de la parroquia que tenían algún bien de fortuna concentraban una proporción bastante alta de su patrimonio en la adquisición de objetos de confort, de refinamiento y suntuarios, y una proporción de su patrimonio especialmente elevada en la adquisición de objetos suntuarios de lujo y joyas, no se habrían preocupado en poseer una amplia variedad de estos objetos.

Tabla 3

Índice de Nivel de Vida (INV) de familias en parroquia La Cañada, 1804-1860

\begin{tabular}{|c|c|c|c|c|c|}
\hline Caso & $\begin{array}{c}\text { Primera } \\
\text { necesidad }\end{array}$ & Confort & Refinamiento & Suntuarios & $I N V$ \\
\hline 1 & 6.5 & 12.5 & 10.6 & 11.3 & 40.9 \\
\hline 18 & 4.7 & 10.0 & 14.1 & 3.8 & 32.6 \\
\hline 16 & 5.3 & 10.0 & 5.3 & 11.3 & 31.9 \\
\hline 19 & 4.7 & 7.5 & 3.5 & 13.1 & 28.8 \\
\hline 4 & 7.1 & 12.5 & 7.1 & - & 26.7 \\
\hline 6 & 4.1 & 7.5 & 3.5 & 9.4 & 24.5 \\
\hline 13 & 3.5 & 7.5 & 5.3 & 7.5 & 23.8 \\
\hline 7 & 4.7 & 5.0 & 5.3 & 1.9 & 16.9 \\
\hline 10 & 2.4 & - & - & 13.1 & 15.5 \\
\hline 17 & 3.5 & 2.5 & 5.3 & 1.9 & 13.2 \\
\hline 20 & 2.9 & 2.5 & 1.8 & 3.8 & 11.0 \\
\hline 9 & 0.6 & 7.5 & 1.8 & - & 9.9 \\
\hline 11 & 2.9 & 2.5 & 1.8 & - & 7.2 \\
\hline 22 & 3.5 & - & 1.8 & 1.9 & 7.2 \\
\hline 8 & 2.4 & - & 3.5 & - & 5.9 \\
\hline 21 & - & - & - & - & 0.0 \\
\hline Promedio & 3.7 & 5.5 & 4.4 & 4.9 & 18.5 \\
\hline $\begin{array}{l}\text { Fracción del } \\
\text { valor teórico } \\
\text { máximo (\%) }\end{array}$ & 37.0 & 18.3 & 14.7 & 16.3 & \\
\hline
\end{tabular}

proporción relativamente menor de su patrimonio en dicho tipo de objetos), mientras que los valores superiores a 1 indican que el valor proporcional de los objetos dentro de la categoría era superior a la cantidad relativa de dichos objetos (es decir, las familias concentraban una proporción relativamente mayor de su patrimonio en dicho tipo de objetos). 


\section{Los objetos de primera necesidad}

Como se ha señalado, los objetos de primera necesidad eran los más numerosos, después de los objetos de trabajo, con un máximo de 87 de ellos por vivienda. ${ }^{39}$ Dentro de esta categoría, los útiles de cocina más frecuentes habrían sido los recipientes de cobre o de hierro destinados a la cocción de alimentos y las piedras de moler maíz y/o de moler pan o pilón de amasar, registrados en un $75 \%$ de las viviendas, con una media de 3.5 objetos del primer tipo y 2.1 del segundo tipo. La presencia de piedras de moler maíz y/o de moler pan o pilón de amasar en la mayoría de las viviendas de la parroquia indicaría que los alimentos fabricados con harina de maíz, como por ejemplo la arepa, los bollitos rellenos de carne, el majarete y el arroz de maíz, consumidos actualmente en el lugar, ${ }^{40}$ habrían sido también de consumo generalizado en la parroquia en los años 1804-1860. ${ }^{41}$ Objetos de cocina de otro tipo, como los utensilios para diferentes modos de cocción de alimentos o piedras de moler cacao/chocolate, que indicarían unas prácticas culinarias más diversificadas, eran al parecer mucho menos frecuentes.

Como fijadores de estándares, los útiles de cocina utilizados en la preparación de alimentos habrían sido objetos de bajo perfil, que habrían ayudado a tejer la fábrica invisible de lo "normal" y de lo "natural" en la parroquia. A modo de ejemplo, para la época los modelos de género atribuían a la mujer una subjetividad específica que las relegaba al ámbito de lo doméstico, asignándoles responsabilidades ligadas a la preparación y conservación de los alimentos dedicados al consumo familiar. ${ }^{42}$ En las viviendas de la parroquia

(ianas, pp. 91, 93)

42 Rincón Rubio, Mujer y honor en Maracaibo a fines del siglo XIX (1880-1900). En este sentido, señala José María Rivas a fines del siglo xix que en las áreas rurales del estado Zulia, como serían los hatos ubicados en la parroquia La Cañada, al llegar un nuevo día los hombres salían de sus respectivas casas en distintas direcciones, unos con sus tercerolas al hombro en pos de presas de cacería, otros con sus instrumentos de labranza a trabajar la huerta, y otros a sabanear en pos de bestias y ganado desperdigado, y los hijos varones salían unos a encaminar las cabras, otros a ayudar a su padre en el trabajo de las huertas, mientras que las mujeres se dedicaban a los quehaceres de la casa (Rivas, Costumbres Zulianas, p. 91). Así mismo, indica Rivas que durante el descanso luego del almuerzo, las mujeres se dedicaban a lavar las ollas y la humilde vajilla, a desgranar el maíz que preparaban para el pan de la cena y a curar las aves de corral empestadas (Rivas, Costumbres Zulianas, p. 94). 
La Cañada, el área de la cocina estaba por lo general segregada de la "casa principal" o "casa de habitación". ${ }^{43} \mathrm{La}$ utilización cotidiana de los objetos domésticos destinados a la preparación de los alimentos por parte de las mujeres de la parroquia habría contribuido así a una segregación espacial por género, y a crear a su vez en las mujeres y en los integrantes masculinos de la unidad doméstica una reacción de conformidad con los estándares y las reglas vigentes de comportamiento.

Sólo en un número minoritario de casos se registró la presencia de recipientes para contener alimentos y vajilla básica. No parece razonable que tales objetos hayan estado ausentes de la mayor parte de las viviendas de la parroquia, al ser esenciales para el almacenaje y el consumo de alimentos. Es probable que al tratarse de objetos de poco valor, hayan sido ignorados por los peritos evaluadores. No se registró tampoco en los inventarios la presencia de cubiertos que no fuesen de plata, como cucharas o cuchillos de hierro, cobre o madera. Como se verá más adelante, los cubiertos de plata estarían presentes en aproximadamente la mitad de las viviendas. ${ }^{44}$ De no haberse encontrado cubiertos elaborados con materiales menos valiosos, ello indicaría que los habitantes de muchas de las viviendas de la parroquia habrían tomado los alimentos directamente con las manos, o bien ayudados con pocillos o escudillas, estos últimos presentes en un $19 \%$ de las viviendas. ${ }^{45}$

Por su parte, los objetos de descanso más frecuentes habrían sido los catres o camas de viento de lienzo, presentes en un $70 \%$ de las viviendas con una media de 1.1 por vivienda, y los catres de viento de cuero, registrados en un $37.5 \%$ de las viviendas con una media de 1.5 por vivienda. ${ }^{46}$ Cuando se registraron camas de viento de lienzo o de cuero la media era de 1.9 de ellas por vivienda, con un mínimo de una cama y un máximo de cuatro camas en un único caso. ${ }^{47} \mathrm{La}$ ropa

43 Rincón Rubio, "Cultura material y vivienda doméstica...".

44 Los cubiertos de plata fueron clasificados aquí bajo la categoría de objetos de refinamiento.

45 La práctica de tomar los alimentos directamente con las manos o ayudados con pocillos o escudillas era común en sociedades rurales de España y de Hispanoamérica en el siglo XIX (Hernández López, "Pautas de consumo doméstico en las tierras de la Mancha oriental (1620-1850)", pp. 159-187. Correa y Wibaux, "Sabores de la pampa. Dieta y hábitos de consumo en la frontera bonaerense", pp. 71-86).

46 En un único caso se registró una hamaca con un valor de 5 pesos, señalándose que era "de bastante uso" (ARPEZ. Civiles. C-197-10 [1848]). Llama la atención que no se registrara en los inventarios con mayor frecuencia la presencia de hamacas, dado que relaciones de la época indican que era éste uno de los soportes utilizados para dormir en los hatos ubicados en las áreas rurales del estado Zulia (Rivas, Costumbres Zulianas, p. 91). No es de descartar que las hamacas hayan estado presentes en un mayor número de viviendas, y que hayan sido subregistradas en los inventarios de bienes debido quizás a que por la condición de desgaste en que se encontraban se les considerara de escaso valor.

47 ARPEZ. Civiles. C-12-9 [1820]. Por "catre" se entendía para la época una cama ligera para dormir una sola persona, con sus largueros y demás piezas plegables para poderse llevar y 
de cama era casi inexistente, registrándose en un único caso una "cobija de dos telas" por valor de cinco pesos. ${ }^{48}$ No se registraron muebles de dormir que por su descripción pudieran considerarse más elaborados o confortables, como cujas matrimoniales, que sí estaban presentes en ocasiones en otras viviendas de la época, tanto en Venezuela como en otros lugares de Hispanoamérica. ${ }^{49}$ Ello indicaría que los residentes de la parroquia La Cañada habrían dormido en muebles bastante básicos.

Dado que el tamaño medio de la familia o unidad doméstica en la parroquia para la tercera década del siglo XIX era de 7.66 individuos, ${ }^{50}$ la media de 1.9 camas de viento de lienzo o de cuero por vivienda indicaría que las camas y/o catres habrían sido utilizadas sólo por algunos miembros de la familia, quizás por la unidad conyugal principal, mientras que la mayor parte de los integrantes de la familia habrían dormido probablemente sobre el suelo, quizás cubierto con esteras de paja, cueros u otro material. ${ }^{51}$ El privilegio de utilizar una cama o un catre como objeto de descanso habría contribuido así a afirmar y reproducir jerarquías generacionales o de género existentes al interior de las unidades domésticas. Aunque en los tratados de urbanidad de la época se intentaba atribuir al cuarto de dormir un carácter de intimidad y privacidad, indicándose como deseable, por ejemplo, que sala de recibo y alcoba no estuvieran jamás una junto a la otra, ${ }^{52}$ en la parroquia La Cañada el cuarto utilizado como dormitorio principal se encontraba adyacente a la sala de las

usar cómodamente (Cf. Diccionario de la lengua castellana por la Academia Española).

Civiles. C-197-10 [1848]. La escasa mención de ropa de cama en los inventarios de bienes, así como la ausencia total de colchones, podría deberse a que para la época, el vocablo "cama" podía aludir a la armazón de madera o hierro junto al colchón y ropa de cama (sábanas, manta o colcha) (Diccionario de la lengua castellana por la Academia Española). La escasa mención de ropa de cama podría indicar también que ésta no era utilizada generalmente en la parroquia, o bien, que de ser utilizada, se encontrara tan desgastada al momento de realizar los inventarios de bienes que no fuese considerada de suficiente valor como para ser incluida en los mismos

49 Moreyra, "La alcoba, el lecho, lo cotidiano...", pp. 95-117. Rivas, El repertorio clásico en el mobiliario venezolano Siglos XVIII y XIX. Duarte, Mobiliario y decoración interior durante el período Hispánico Venezolano.

50 Rincón Rubio, La Inmaculada Concepción de La Cañada. Orígenes, estructura familiar y prácticas sociales (1688-1838).

51 En este sentido, escribe José María Rivas a finales del siglo xix que en los hatos ubicados en las áreas rurales del estado Zulia, como serían los hatos ubicados en la parroquia La Cañada, los chicos de las unidades domésticas dormían "regados por los rincones, unos en duros lechos formados por el suelo, otros en sus hamacas ó chinchorros donde á penas caben" (Rivas, Costumbres Zulianas, p. 91).

52 Carreño, Manual de urbanidad y buenas costumbres para uso de la juventud de ambos sexos; en el cual se encuentran las principales reglas de civilidad y etiqueta que deben observarse en las diversas situaciones sociales. 
viviendas. ${ }^{53}$ Ello pudo haber resultado en una escasa diferenciación entre los ámbitos público y privado en las viviendas de la parroquia.

Eran también frecuentes las mesas y los taburetes, sillas y banquetas, presentes en un $70 \%$ de las viviendas, con una media de 8.3 de ellos por vivienda. Al igual que los útiles de cocina, estos objetos de descanso habrían ejercido agencia material como fijadores de estándares en la parroquia. Se ha indicado, por ejemplo, que en las sociedades hispanoamericanas de la época eran los hombres quienes tenían el privilegio de sentarse a la mesa, sobre todo si las sillas eran escasas. ${ }^{54}$ Es posible también que las personas mayores hayan tenido ciertos privilegios en este sentido. Por otro lado, como hemos visto, a las mujeres correspondía la responsabilidad de preparar y servir los alimentos. De esta forma, al ser utilizados preferentemente por unos o por otros a la hora de comer, estos objetos de descanso habrían contribuido a expresar y a fortalecer las jerarquías de género o generacionales dentro del grupo familiar. Tener el privilegio de sentarse en una silla o taburete con espaldar, en lugar de en una banqueta, pudo haber afianzado también estas jerarquías al interior de las unidades domésticas.

Como objetos de gestión predominarían los baúles, presentes en un mayoritario $62.5 \%$ de los casos, con una media de 2.7 de ellos por vivienda. ${ }^{55}$ En varios casos se menciona que se trataba de baúles "grandes" con sus patas o bancos y cerradura. En un único caso se indican las medidas de dos baúles inventariados, siendo éstas de una vara y tercia de largo y media vara de ancho para uno de ellos, y tres cuartas varas de largo y media vara de ancho para el otro. ${ }^{56} \mathrm{En}$ algunos casos se indica que el baúl estaba forrado de cuero o cordobán. ${ }^{57}$ Como se verá más adelante, se registraron en las viviendas muy pocos muebles de guardar de otros tipos, como escaparates, cómodas o armarios, por lo que es de pensar que los baúles se utilizarían para almacenar una gran diversidad de artículos. Mientras los baúles eran muebles con poca diferenciación y compartimentación, otros muebles de guardar

53 Rincón Rubio, “Cultura material y vivienda doméstica en una parroquia rural...”, pp. 106-146.

54 Moreyra, "Cocinar y comer en la Córdoba (Argentina) del siglo XIX. Una lectura de la cultura material doméstica", pp. 262-294.

55 En varios casos se menciona que se trataba de baúles "grandes" con sus patas o bancos y cerradura. En un único caso se indican las medidas de dos baúles inventariados, siendo éstas de una vara y tercia de largo y media vara de ancho para uno de ellos, y tres cuartas varas de largo y media vara de ancho para el otro (unos 1,08 metros de largo por 0,42 metros de ancho para el primero, y 0,63 metros de largo por 0,42 metros de ancho para el segundo) (ARPEZ. Civiles. C-2-14 [1804]). En algunos casos se indica que el baúl estaba forrado de cuero o cordobán (ARPEZ. Civiles. C-39-1 [1829-1830]).

56 Unos 1,08 metros de largo por 0,42 metros de ancho para el primero, y 0,63 metros de largo por 0,42 metros de ancho para el segundo (ARPEZ. Civiles. C-2-14 [1804]).

57 ARPEZ. Civiles. C-39-1 [1829-1830]. 
como escaparates y armarios eran más compartimentados, y su uso estaría asociado a una organización independiente y más especializada del espacio doméstico. ${ }^{58}$ En este sentido, la presencia generalizada de baúles y la ausencia casi total de escaparates y armarios indicarían que la organización del espacio doméstico en la parroquia en los años 1804-1860 era muy poco diferenciada o especializada. ${ }^{59}$

En ningún caso se inventariaron objetos de vestimenta básica como ropa o pañuelos. Dado que los habitantes de la parroquia tendrían que utilizar algún tipo de vestimenta, su total ausencia en los inventarios de bienes podría indicar que se trataba de objetos escasos y quizás muy desgastados. Por otra parte, al tratarse de objetos de uso muy personal, quizás se consideraba difícil obtener de ellos algún monto monetario. Es posible también que de haber estado presentes en las viviendas, éstos y otros objetos de uso muy personal o de escaso valor hayan sido donados a familiares del difunto y excluidos por ello de los inventarios de bienes.

\section{Objetos de confort}

Los objetos de confort eran poco numerosos, registrándose una media de sólo 4.3 de ellos por vivienda, con un máximo de 12 objetos en una de las viviendas. ${ }^{60}$ El mobiliario más frecuente indicativo de un cierto grado de confort eran los sillones, butacas y sillas de brazos, registrados en un $44 \%$ de los casos, con una media de aproximadamente tres de ellos por vivienda. Estos muebles habrían permitido una postura más cómoda que los taburetes y las banquetas, al posibilitar apoyar tanto la espalda como los brazos. Dado que estaban presentes en pequeñas cantidades, es posible que se reservaran para los dueños de casa o para invitados importantes.

59 No es posible conocer la ubicación concreta de los objetos de primera necesidad en los diferentes ambientes de las viviendas, dado que los inventarios post-mortem no suministran dicha información. Es lógico inferir que los útiles de cocina se encontrarían en la cocina de las viviendas, y quizás también en el cuarto utilizado como despensa que se encontraba por lo general contiguo a la cocina, mientras que objetos de descanso como catres o camas de viento de lienzo o de cuero se encontrarían probablemente en el cuarto/dormitorio principal de las viviendas, y en otros ambientes utilizados también como dormitorio. Objetos de descanso como mesas y taburetes, sillas y banquetas, así como objetos de gestión como baúles y estantes pudieron ubicarse en los diferentes ambientes de las viviendas: sala, cuartos, cocina y enramada (Cf. Rincón Rubio, "Cultura material y vivienda doméstica en una parroquia rural...", pp. 106-146). 
En un minoritario $38 \%$ de las viviendas se registró también algún objeto de mobiliario asociado con la organización del espacio o de pertenencias personales, como por ejemplo un estante de cedro en un caso, ${ }^{61}$ un escaparate en un caso ${ }^{62}$ y un biombo, también en un caso, ${ }^{63}$ con una media de sólo 1.6 objetos de este tipo por vivienda. La ausencia casi total de muebles cerrados de guardar y la escasa presencia de muebles utilizados para la organización del espacio indicaría, como hemos comentado, que la organización del espacio doméstico en la parroquia en los años 1806-1860 habría sido poco diferenciada o especializada. La presencia de un biombo en uno de los casos habría indicado el deseo de sus propietarios de generar espacios de cierta intimidad dentro de los ambientes de la vivienda. Por otro lado, la ausencia de mobiliario asociado a la escritura y la lectura, tales como escritorios y estantes para libros, indicaría que dichas prácticas, que implicarían un grado de educación superior al común, habrían sido poco frecuentes en la parroquia en el período en cuestión. El mobiliario de madera fina como mesas, camas o rinconeras de cedro o de caoba estaría presente en un pequeño $6.3 \%$ de las viviendas, con una media de un único objeto de este tipo por vivienda.

Las planchas eran frecuentes, habiéndose registrado en un 38\% de las viviendas; es de pensar que éstas se hayan utilizado principalmente para alisar la vestimenta de uso personal, que sin embargo, como hemos visto, estaba ausente de los inventarios de bienes. Otros objetos que hemos considerado de confort, como muebles de cedro o caoba, cafeteras o molinos de café y aguadores eran también escasos, habiéndose registrado en menos del $10 \%$ de las viviendas. Es extraño que sólo se documentaran poncheras y bateas de lavar en un $6 \%$ de los casos. Al igual que pudo haber sucedido con otros objetos menores, es posible que los objetos para lavar hayan sido excluidos de los inventarios de bienes debido a su poco valor o al grado de desgaste en que se encontraban. En ninguna de las viviendas de la parroquia se registraron paraguas ni quitasoles.

En general, el bajo porcentaje de viviendas en las que se inventariaron objetos de confort, aunado a su escasa cantidad, indicaría que las actividades cotidianas en las viviendas de la parroquia La Cañada se habrían desenvuelto en un marco material bastante limitado. ${ }^{64}$ Actuando materialmente como

\footnotetext{
ARPEZ. Civiles. C-132-15 [1841].

ARPEZ. Civiles. C-255-16 [1857].

ARPEZ. Civiles. C-86-2 [1832].

No es posible tampoco conocer con precisión dónde se habrían ubicado los diferentes objetos de mobiliario de confort en las viviendas de la parroquia. Es de pensar que mientras que camas de cedro o de caoba y escaparates se ubicarían en el cuarto o dormitorio principal de las viviendas, otros muebles como sillones, butacas y/o sillas de brazos, muebles de cedro o caoba como mesas y rinconeras, y otros muebles como cómodas, estantes con cornisa, rinconeras, o escritorios pudieron ubicarse en las salas de las viviendas.
} 
fijadores de estándares, los objetos de confort habrían ayudado también a crear los ambientes y los escenarios apropiados para que se desarrollara la vida cotidiana en la parroquia, reproduciendo significados ampliamente compartidos y creando una reacción de conformidad o aceptación inconsciente de estos significados. Como hemos mencionado los modelos de género vigentes para la época asignaban a la mujer atribuciones ligadas a las labores domésticas, hecho que se afirmaba con el uso cotidiano que éstas daban a objetos como cafeteras y molinos de café, planchas y bateas o poncheras de lavar. Por otro lado, el uso de las butacas y de las sillas de brazos pudo ser exclusivo o preferente de algunos miembros de la unidad doméstica, como por ejemplo los integrantes de la unidad conyugal principal, o de ciertos visitantes, lo cual pudo haber reforzado también jerarquías sociales, de género o generacionales. Es también posible que algunos de los objetos que hemos considerado de confort, como sillones, butacas y muebles de cedro, actuaran materialmente como tecnologías de encantamiento, y que algunas familias de la parroquia se rodearan de este tipo de objetos buscando, consciente o inconscientemente, demostrar la posesión de distinción en sus maneras sociales.

\section{Objetos de refinamiento}

Se relacionaron en promedio 7.4 objetos de refinamiento en las viviendas de la parroquia, con un máximo de 18 de ellos por vivienda. ${ }^{65}$ Los cubiertos de plata serían los objetos más frecuentes dentro de esta categoría, al estar presentes en un $50 \%$ de las viviendas, con una media de 5.4 de ellos por vivienda. ${ }^{66}$ Este número promedio de cubiertos de plata por vivienda no es muy diferente al

ARPEZ. Civiles. C-12-9 [1820], C-255-2 [1846].

66 Para 1837, por "cubierto" se entendía "el servicio de mesa que se pone á cada uno de los que han de comer, compuesto de plato, cuchillo, tenedor y cuchara, pan y servilleta", pudiendo entenderse también con dicha palabra un "juego compuesto de cuchara, tenedor y cuchillo" (Diccionario de la lengua castellana por la Academia Española). En los inventarios de bienes realizados en la parroquia La Cañada los cubiertos de plata fueron registrados en ocasiones con la denominación general de "cubiertos de plata" (ARPEZ. Civiles. C-3710 [1827-1828]), mientras que en otras ocasiones se especificó en mayor detalle el tipo de objeto, indicándose por ejemplo que se trataba de "dos cubiertos de cucharas y tenedores" (ARPEZ. Civiles. C-2-14 [1804]), de "cuatro tenedores y dos cuchillos" (ARPEZ. Civiles. C-197-10 [1848]), o "nueve cucharas de plata" (ARPEZ. Civiles. C-123-2 [1840]). Dada la variedad existente en la manera de registrar estos objetos, es difícil saber con exactitud a qué se referían los peritos evaluadores cuando escribían "cubiertos de plata" en un inventario de bienes. Es posible que al indicar "cubiertos de plata" los peritos evaluadores se hayan referido tanto a un conjunto compuesto por cuchara, tenedor y cuchillo, como a cualquier combinación de ellos. Es de destacar, sin embargo, que en los casos en los que se especifica el tipo de cubierto es mucho más frecuente la mención de cucharas y tenedores de plata, que la mención de cuchillos. Esto podría indicar que los primeros eran de uso más extendido en la parroquia. 
tamaño promedio de la unidad doméstica en la parroquia para el año 1834 , que como hemos señalado era de 7.66 individuos por unidad doméstica. Ello implicaría que en las familias que poseían cubiertos de plata, la mayor parte de sus integrantes tenían acceso a utilizar un cubierto al momento de sentarse a la mesa para el desayuno, el almuerzo o la cena, sin necesidad de compartirlo con otros miembros de la unidad doméstica. Siguiendo a Elías, ${ }^{67}$ ello podría indicar a su vez que en estas familias se habría materializado una regulación de los impulsos y de las emociones asociadas con el desagrado que produce ensuciarse los dedos al momento de comer, o el mostrarse ante otros con los dedos sucios o grasientos.

Dada la escasa presencia de otros objetos de refinamiento, los cubiertos de plata habrían sido los principales objetos de este tipo que muchas de las familias de la parroquia La Cañada habrían podido exhibir en sus viviendas como objetos indicativos de una cierta distinción o elegancia en sus prácticas sociales.$^{68}$ Como tecnologías de encantamiento, al incorporar en su diseño un costo relativamente elevado y un material de disponibilidad limitada como la plata, estos objetos habrían actuado sobre los agentes sociales que los utilizaban y que interactuaban con ellos, induciendo reacciones o respuestas emocionales asociadas a la afirmación o al reconocimiento de pretensiones de prestigio o de valía social de sus propietarios. Otros objetos de mesa que hemos considerado de refinamiento, tales como jarras, vasos y copas de cristal, o soperas, platones y platos finos, aunque bastante escasos al haber sido registrados en menos de un $12 \%$ de las viviendas, habrían podido ejercer agencia material como tecnologías de encantamiento, en el sentido antes indicado. En ningún caso se documenta en los inventarios de bienes la presencia de manteles o de servilletas, lo cual podría indicar que su uso no era común en la parroquia.

Los objetos de decoración eran al parecer muy escasos, al haber sido registrados sólo en un $19 \%$ de los casos; cuando estaban presentes había en promedio cuatro de ellos por vivienda, tratándose siempre de cuadros o esculturas de carácter religioso. Estos objetos, además de ser indicativos de devoción religiosa, pudieron haber materializado el gusto de sus propietarios

67 Elías, El proceso de la civilización. Investigaciones sociogenéticas y psicogenéticas. Moreyra, "Cocinar y comer en la Córdoba (Argentina) del siglo XIX...", pp. 262-294.

68 La presencia de cubertería de plata en viviendas rurales y urbanas de sociedades hispanas e hispanoamericanas de los siglos XVIII y XIX ha sido identificada por diferentes investigadores; en general, se ha señalado que estos objetos eran un elemento visible de la posición social y económica que ocupaba la familia de cara a la sociedad (cf. Moreyra, "Cocinar y comer en la Córdoba (Argentina) del siglo XIX...", pp. 262-294. Bartolomé Bartolomé, "Patrimonios, condiciones de vida y consumo. La burguesía administrativa y las profesiones liberales en la ciudad de León. 1700-1850”, pp. 73-89. Sánz de la Higuera, “Aproximación a la mesa de los burgaleses. Cuberterías y platos en el setecientos”, pp. 183-195. Hernández López, "Pautas de consumo doméstico...", pp. 159-187). 
por la estética y el arte. De haber estado colocados en las áreas de mayor intercambio social con visitantes, como por ejemplo la sala de las viviendas, habrían actuado como tecnologías de encantamiento, exhibiendo la religiosidad y el gusto por lo bello de sus propietarios. Más escasos aún eran los libros, los cuales fueron registrados en un único caso, correspondiente a una vivienda de hato playero, en la que se documentaron cuatro libros de navegación, un libro de moral cristiana y un libro probablemente de medicina doméstica. ${ }^{69}$ Tal como se dedujo ante la carencia de mobiliario asociado a la escritura y a la lectura, la ausencia casi total de libros en los inventarios de bienes realizados en las viviendas de la parroquia indicaría que la lectura habría sido una práctica muy poco común en el lugar durante el período en cuestión. ${ }^{70}$

Dada su escasa presencia en los inventarios post mortem, los objetos de higiene fueron considerados en esta investigación como objetos de refinamiento. Se asumió que dada su rareza, la presencia de los mismos en una vivienda indicaría que sus propietarios habrían tenido un grado de preocupación en cuanto al cuidado del cuerpo por encima del común, lo cual pudo haber implicado también un refinamiento más general en las maneras sociales.

Durante la primera mitad del siglo XIX, cambios en las sensibilidades y en los umbrales de la vergüenza y el desagrado que venían dándose en el mundo occidental desde finales del siglo XVIII resultarían en la aparición de reglas de urbanidad dirigidas a conformar sociedades "civilizadas" y personas "cultas", y en la construcción de prácticas y percepciones relativas al aseo corporal que pasarían a insertarse en forma gradual en el ámbito de la salud y la medicina. ${ }^{71}$ En este sentido, manuales de urbanidad que circularían en la Venezuela de mediados del siglo XIX, además de considerar el aseo en general como una base

ARPEZ. Civiles. C-255-2 [1846]. En este inventario post-mortem, correspondiente a los bienes de Tomás Vega, se registraron seis libros, uno de ellos identificado como "Un Buchan viejo". Es posible que este libro haya sido un ejemplar de la obra de Jorge Buchan titulada Medicina doméstica, o Tratado completo del método de precaver y curar las enfermedades con el régimen, y medicinas simples, y un apéndice que contiene la farmacopea necesaria para el uso de un particular (Buchan, Medicina doméstica), el cual fue al parecer muy popular en el mundo hispanoamericano en el siglo XIX (cf. Alzate Echeverri, "Los manuales de salud en la Nueva Granada (1760-1810) ¿El remedio al pie de la letra?”, pp. 209-252. Hersch Martínez, "Tres textos de medicina en México: Velasco, Barajas y López Tilgham", pp. 11-18).

70 En documentos generados en la parroquia La Cañada durante la primera mitad del siglo XIX se observa que muchas de las personas que suscribían dichos documentos no sabían firmar (Rincón Rubio, La Cañada de Urdaneta. Documentos para su historia (1836-1936)). Los establecimientos de instrucción pública o privada, donde se habría aprendido a leer y a escribir, fueron muy escasos en la parroquia La Cañada durante la primera mitad del siglo XIX (Rincón Rubio, La Cañada de Urdaneta. Documentos para su historia (1836-1936)).

71 Moreyra, Cecilia, "Cultura material e higiene cotidiana en la Córdoba del Ochocientos", pp. 211-234. 
importante de la estimación social, resaltaban que el aseo contribuía también poderosamente a la conservación de la salud. ${ }^{72}$ Estos manuales incluían minuciosas recomendaciones referentes al aseo de los vestidos y de las habitaciones de las viviendas, así como referentes al aseo personal. En cuanto a este último, se recomendaba, por ejemplo, la adopción del lavado cotidiano de la cara, los ojos, los oídos, el cuello, la cabeza y las manos como una práctica principal, así como acostumbrarse a los baños generales al menos una vez a la semana, descritos estos últimos como aquéllos en los que se introducía todo el cuerpo en el agua con el objeto de asearse. ${ }^{73} \mathrm{El}$ hecho de que los manuales de urbanidad instaran a habituarse a los baños generales podría indicar que ésta no era una práctica generalizada en la Venezuela de mediados del siglo XIX. ${ }^{74}$

Los objetos de higiene registrados con mayor frecuencia en las viviendas de la parroquia La Cañada durante el período 1804-1860 serían los del subgrupo de bacines y cajas o vasos excretorios, y/o escupideras, visitadoras (enemas) y ventosas, registrados en un $31 \%$ de los casos, con una media de 1.6 de ellos por vivienda. ${ }^{75}$ Cuando estaban presentes, dada su escasa cantidad, habrían tenido que ser compartidos por los diferentes integrantes de la unidad doméstica, o ser utilizados únicamente por algunos de ellos. Estudios recientes han encontrado que las viviendas de la parroquia carecían de ambientes identificados como cuartos de baño, y de ambientes que se pudiera inferir que hubieran sido utilizados exclusivamente para las actividades referentes al aseo personal o para actividades relacionadas con las necesidades fisiológicas. ${ }^{76}$ Esto indicaría que las actividades de aseo personal pudieron haberse realizado indistintamente en los diferentes ambientes o "cuartos" de dichas viviendas. Es posible que los bacines y las cajas o vasos excretorios que fueron registrados en un $25 \%$ de los casos hayan sido utilizados para satisfacer necesidades fisiológicas,

72 Carreño, Manual de urbanidad y buenas costumbres..., p. 18.

73 Ídem.

74 Durante la expansión de la peste negra en la Europa medieval se afianzaría una mentalidad reticente al baño, al concebirse el agua como un elemento penetrante, capaz de abrir los poros de la piel dejando a la persona permeable al aire corrupto, e indefenso frente a las enfermedades; así mismo, se pensaba también que el agua dejaba escapar los humores y vigores del cuerpo (Moreyra, "Cultura material e higiene cotidiana...", pp. 211-234). Dado que se pensaba que el agua desequilibraba, debilitaba y enfermaba, se desaconsejaba el baño. Al considerar los poros de la piel como la puerta de entrada de las enfermedades, se pensaba que sólo era posible protegerse vistiendo capas compactas de ropa. Y en consecuencia, se consideraba que para mantener limpio el cuerpo bastaba con lavar la ropa que lo envolvía. Estas ideas estaban presentes también en la Hispanoamérica de los siglos XVIII y XIX (Moreyra, "Cultura material e higiene cotidiana...", pp. 211-234).

75 Por "bacín" se entendía para la época un vaso de barro vidriado alto y redondo que servía para recibir los excrementos del cuerpo humano (Diccionario de la lengua castellana por la Academia española).

76 Rincón Rubio, “Cultura material y vivienda doméstica en una parroquia rural...”, pp. 106-146. 
por ejemplo, en los cuartos dormitorios, para luego ser arrojado su contenido en algún lugar exterior destinado a ese fin. Algunas necesidades fisiológicas pudieron haberse satisfecho directamente en letrinas o pozos que sirvieran a las funciones de excreción, separados del área residencial de las viviendas, o quizás en áreas descampadas. ${ }^{77}$ Es de destacar que no se inventarió ninguna escupidera en las viviendas de la parroquia. ${ }^{78}$

En una cuarta parte de los casos se registraron lebrillos de madera o vidriados, con una media de 2.3 de ellos por vivienda, y en sólo dos casos $(12.5 \%$ del total) se documentaron aguaduchos o aguamaniles, con una media de uno por vivienda, objetos que habrían sido utilizados para la limpieza y el lavado de la cara, las manos y otras partes del cuerpo. Dado que el tamaño promedio de las unidades domésticas de la parroquia para el año 1834 era de 7.66 individuos, estos objetos habrían sido compartidos por quienes las integraban.

Las tinas o bateas de baño eran, al parecer, casi inexistentes en las viviendas de la parroquia, registrándose sólo una de ellas en un único caso. ${ }^{79}$ Ello indicaría que la higiene personal de los habitantes de la parroquia La Cañada durante los años 1804-1860 se habría limitado al lavado de algunas partes del cuerpo mediante la utilización de lebrillos u objetos similares. Al igual que en otras regiones de Venezuela y de Hispanoamérica, ${ }^{80}$ la práctica del baño de cuerpo completo habría sido poco extendida en la parroquia. Otros objetos de aseo e higiene personal como navajas de afeitar, espejo, tijeras finas y/o bacinilla o ponchera de afeitar fueron registrados en un minoritario $12.5 \%$ de

Algunos hatos playeros de la parroquia contaban con espacios construidos auxiliares a la vivienda principal (casitas o cuartos en la playa), que pudieron también haber sido utilizados para este propósito (cf. Rincón Rubio, "Cultura material y vivienda doméstica en una parroquia rural...", pp. 106-146).

78 Las escupideras estaban destinadas a contener la saliva que escupían las personas, y se utilizaban para mantener la limpieza y el orden, en cuanto que evitaban que se escupiera en el suelo de las viviendas. Elías, El proceso de la civilización. Investigaciones sociogenéticas y psicogenéticas, ha indicado que la escupidera tenía una gran importancia en el siglo XIX en el interior de las casas en el mundo occidental, en correspondencia con el avance de los límites de la repugnancia. De no haber existido este tipo de objetos en las viviendas de la parroquia La Cañada, ello no indicaría necesariamente que los residentes de la parroquia acostumbraran escupir sobre el suelo de las viviendas, ya que es posible que se utilizara otro tipo de objetos o envases con el mismo propósito.

79 ARPEZ. Civiles. C-206-6 [1850].

80 En ciudades como Medellín (Colombia), el hábito de aseo diario hasta finales del siglo XIX y principios del siglo xx sería el lavado de manos y cara; la implantación del baño diario sólo se logró lentamente a partir de principios del siglo xx, acompañado de numerosas recomendaciones en manuales de higiene y urbanidad acerca de cómo realizarlo, lo cual indica que habían muchas reticencias y temores que era necesario vencer para lograr la instauración de ese hábito (cf. Reyes Cárdenas, Aspectos de vida social y cotidiana en Medellín, 1890-1930). 
las viviendas, con una media de cuatro de ellos en dichas viviendas. La barba en los hombres, considerada entonces como un signo de virilidad, de poder, valor y coraje, debía cuidarse para que pudiera ser un signo de "civilización". ${ }^{81}$ No es de descartar que los objetos de afeitar hayan estado presentes en un mayor número de viviendas, y que hayan sido excluidos de los inventarios de bienes por las razones antes comentadas para otros tipos de objetos.

En sólo tres casos $(18.8 \%$ del total) se relacionó la presencia de vestimenta no básica, a saber, ropa masculina o femenina de paño, lana y/o seda, y/o sombreros, ${ }^{82}$ con una media de un único objeto de este tipo en dichas viviendas. Ello indicaría que este tipo de vestimenta habría sido poco común en la parroquia, al menos vestimenta que se encontrase en suficiente buen estado y fuese considerada de algún valor como para ser incluida en los inventarios de bienes. En sólo tres casos se registró la presencia de cajas habaneras (una por vivienda), que habrían sido utilizadas para guardar y conservar habanos $\mathrm{u}$ otros productos de tabaco. El fumar tabaco era, al parecer, una práctica común en las áreas rurales vecinas a la ciudad de Maracaibo; ${ }^{83}$ la presencia de cajas habaneras en un minoritario número de casos no indicaría necesariamente que el fumar tabaco haya sido una práctica poco frecuente en la parroquia $\mathrm{La}$ Cañada, ya que es posible que estos productos hayan sido almacenados en recipientes de uso general.

Otros objetos que hemos considerado de refinamiento, como por ejemplo relojes de sol, tinteros, escribanías, papeleras y/o resmas de papel, y objetos como espejos, espejuelos, anteojos de larga vista estarían presentes en un porcentaje muy pequeño de las viviendas, mientras que en ninguna de las viviendas representadas en los inventarios de bienes se registraron relojes de faltriquera o instrumentos musicales. Todo ello indicaría que en general, las familias que habitaban en la parroquia La Cañada durante los años 18041860 se habrían desenvuelto en un marco material en el que habrían escaseado

81 Moreyra, "Cultura material e higiene cotidiana en la Córdoba del Ochocientos", pp. 211-234. Así lo consideraban los manuales de urbanidad de la época, que indicaban que quienes se dejaran crecer la barba debían peinarla varias veces al día, aconsejando, por otra parte, que el que se afeitaba debía hacerlo diariamente, al considerar que "nada hay más repugnante que esa sombra que da a la fisonomía una barba renaciente, ni hay por otra parte en los hombres un signo más inequívoco de un descuido general en materia de aseo" (Carreño, Manual de urbanidad y buenas costumbres..., p. 21).

82 ARPEZ. Civiles. C-2-14 [1804], C-39-1 [1829-1830], C-255-2 [1846].

83 José María Rivas, narrando a fines del siglo XIX en su obra Costumbres zulianas las prácticas típicas de los habitantes de un hato de las áreas rurales del estado Zulia, como habrían sido los hatos ubicados en la parroquia La Cañada, indica que luego del almuerzo, el jefe de familia cargaba y prendía su cachimba o pipa, y los jóvenes de la familia que ya fumaban iban "a saborear su tabaco donde los padres no los vean, porque sería gran desacato hacerlo delante de ellos" (Rivas, Costumbres zulianas, p. 94). Esto podría indicar que el fumar tabaco era una práctica común entre los habitantes de dichos hatos de las áreas rurales. 
muchos de los objetos de refinamiento vinculados con la cultura occidental urbana. Al igual que los objetos de refinamiento de mesa y de decoración, otros objetos de refinamiento de presencia minoritaria en las viviendas de la parroquia, como libros, vestimenta de paño, de lana o de seda, tinteros y escribanías, que pudieron haberse considerado localmente como indicadores de distinción o de elegancia, habrían actuado como tecnologías de encantamiento sobre los agentes sociales que interactuaban con ellos, tantos pertenecientes a la unidad doméstica como exteriores a ella.

\section{Objetos suntuarios}

En las viviendas de la parroquia La Cañada reflejadas en el corpus documental se registraron en promedio 8.7 objetos suntuarios, con un máximo de 44 de ellos por vivienda ${ }^{84}$ Como se ha mencionado anteriormente, el índice relativo de valor de los objetos suntuarios era muy elevado, lo cual indicaría que las familias en cuestión concentraban en promedio una alta proporción de sus recursos económicos en adquirir objetos de lujo y joyas.

En la subcategoría de objetos de lujo, las armas de fuego finas eran los objetos más frecuentes, registrándose en un 33\% de los casos, con una media de 1.5 de ellas por vivienda. Al tratarse de una parroquia rural, con amplias oportunidades para practicar la cacería, no extraña que las armas finas hayan sido relativamente frecuentes en las viviendas. Les seguían en frecuencia los rosarios de oro y/o perlas, registrados en un $25 \%$ de los casos, con una media de 2.8 de ellos por vivienda. Al igual que los objetos de decoración de temática religiosa antes discutidos, es posible que los rosarios de oro y/o perlas, además de ser indicativos de devoción religiosa, hayan materializado y exhibido el gusto de sus propietarios por la estética. Otros objetos de lujo serían mucho menos frecuentes, como por ejemplo las peinillas o peinetas de carey, registrados en sólo dos casos (aunque presentes en número elevado), y los sables, espadas y dagas guarnecidas, documentados también en sólo dos casos, con una media de dos de ellos por vivienda.

Por otra parte, las cadenas y gargantillas, mancornas de cuello, medallas y cruces de oro eran las joyas más frecuentes, al estar presentes en casi la mitad de los casos, con una media de 2.6 de ellas por vivienda. Les seguían las hebillas y charreteras de pies de oro o de plata, presentes en un $37.5 \%$ de los casos, y los zarcillos, orejeras y aros, peinetas y peinillas engastadas en oro o plata, estos últimos registrados en un 33\% de los casos y en un número bastante alto, con 3.4 de ellos en promedio por vivienda. Joyas como las mancornas y los botones de oro y piedras preciosas, y las sortijas de oro y piedras preciosas, estaban presentes en un $25 \%$ de los casos. Cuando estaban presentes, eran 
numerosas las sortijas de oro y piedras preciosas, con casi ocho de este tipo de joyas en promedio por vivienda.

Tal como ha sido propuesto para otras sociedades rurales occidentales preindustriales, ${ }^{85}$ es posible que la posesión de objetos suntuarios por parte de las familias de la parroquia La Cañada respondiera a una materialización del ahorro en objetos de oro y plata que pudiesen ser fácilmente convertibles en dinero en efectivo, y que habrían ayudado a hacer frente a deudas o a salir de apuros económicos en momentos de falta de liquidez.

Por otro lado, es posible que el elevado índice relativo de valor de los objetos suntuarios haya sido una consecuencia del interés que pudieron tener las familias de la parroquia en poseer y exhibir objetos de lujo y joyas para afirmar pretensiones de valía o de preeminencia social. En este sentido, no es de descartar que factores étnicos hayan jugado un papel significativo en la distinción de grupos sociales en la parroquia hasta bien entrado el siglo XIX. La diferenciación de los habitantes de la parroquia La Cañada en dos grandes grupos étnicos, por una parte la "gente blanca" (denominados también "vecinos españoles" o "gente española blanca"), y por otra parte la "gente de servicio" (que incluía categorías como "moreno libre", "pardo libre", "zambón", "esclavo" e "indio") había sido la regla oficial durante el período monárquico, y continuaría siéndolo en los libros de administración eclesiástica de la parroquia hasta el año $1841 .^{86}$ Durante el período monárquico, la pertenencia al grupo de la "gente blanca" facilitaba y era generalmente necesaria para la adquisición y el mantenimiento del poder, de privilegios, y de honor o prestigio social. La escenificación de la blancura, es decir, la demostración de las formas asociadas a la pertenencia al grupo dominante de los blancos, sería por ello indispensable para la estima y el ascenso dentro del entramado social. ${ }^{87}$ La apariencia personal sería fundamental tanto en la construcción de la subjetividad y la identidad personales, como en el mantenimiento y la reproducción de las jerarquías sociales.

85 Hernández López. “Trastillos de casa pobre. Homenaje de casa decente”, pp. 457-477; "Pautas de consumo doméstico en las tierras de la Mancha oriental (1620-1850)", pp. 159187. Moreno Claverías, "Pautas de consumo y diferenciación social...", pp. 207-245; "Lugar de residencia y pautas de consumo. El Penedés y Barcelona, 1770-1790”, pp. 139-165.

86 El libro donde se asentaban las partidas de matrimonio de la "gente blanca" de la parroquia La Cañada que inició el 21 de abril del año 1821 corrió hasta el mes de octubre de 1841 (APIC. "Libro parroquial donde se asientan las partidas de casamiento de gente blanca perteneciente a la parroquia de la Inmaculada Concepción de La Cañada hecho por su propio párroco Pbro. Lorenzo Romero, comienza a correr el veinte y uno de abril del año de 1825”). A partir del año 1841 se utilizó un único libro para registrar los matrimonios de los habitantes de la parroquia (APIC. Tomo 4 de matrimonios, 1841-1860).

87 Randazzo Ruiz, "La honorabilidad en la apariencia: Teatralidades cotidianas y escenificación de la blancura...”, pp. 427-454. Pellicer, La vivencia del honor en la provincia de Venezuela 1774-1809. 
Un elemento esencial de la escenificación de la blancura mediante la apariencia personal sería el mostrarse a través de objetos y ornamentos que se consideraban de uso exclusivo o característico del grupo étnico dominante, y que materializarían por ello la pertenencia a dicho grupo. Ello incluiría, por ejemplo, el porte de anillos de oro en los dedos de la mano, el porte de collares, cadenas y medallas de oro o plata, y el uso de espuelas y guarniciones de espada doradas ${ }^{88}$ Es de pensar que las representaciones sociales asociadas a esta escenificación de la diferenciación étnica se dieran y permanecieran en la parroquia La Cañada hasta tiempo después de que dicha diferenciación dejara de ser oficialmente sancionada. La casi totalidad de inventarios de bienes de los años 1804-1860 disponibles para esta investigación (15 de los 16 casos) correspondieron a familias que habían sido consideradas como "gente blanca" en la parroquia en los años anteriores a $1841{ }^{89}$ Es entonces posible que para estas familias, el uso y la exhibición de objetos suntuarios haya sido una manera de mostrar y demostrar la pertenencia y la honorabilidad asociada al grupo étnico dominante.

En general, como objetos irresistibles, intrínsecamente valiosos y deseables, los objetos de lujo y las joyas habrían permitido una evaluación de valor relativamente simple por parte de quienes los observaban, y habrían sido fácilmente jerarquizados de acuerdos a criterios obvios como su costo o su brillantez visual. Al ser exhibidos y portados por sus propietarios en lugares privados o públicos de la parroquia, y al evocar mediante sus materiales de elaboración, su confección, y/o su simbolismo valores compartidos de éxito o de preeminencia social, estos objetos habrían inducido en quienes los observaban reacciones o respuestas emocionales que habrían afirmado las demandas o pretensiones de estatus o superioridad social de sus propietarios. Algunos de los propietarios de viviendas en la parroquia La Cañada poseían también viviendas urbanas en la ciudad de Maracaibo,${ }^{90}$ habiéndose registrado en estas últimas un elevado número de objetos suntuarios. Es de pensar que muchos de los objetos suntuarios inventariados en las viviendas urbanas, en especial las joyas, habrían sido portados y exhibidos por sus propietarios cuando pasaban tiempo en sus viviendas de la parroquia La Cañada o cuando socializaban en lugares públicos de la parroquia, actuando materialmente en

$88 \quad$ Ibid.

89 La pertenencia de estas familias a la categoría étnica local de "Gente Blanca" fue establecida por el autor de este artículo mediante un arqueo de los libros de bautismos y matrimonios de la parroquia La Cañada de los años 1785-1860, y de las parroquias El Sagrario y San Juan de Dios de la ciudad de Maracaibo para fines del siglo XVIII y principios del siglo XIX ("Venezuela, registros parroquiales y diocesanos, 1577-1995", database with images, FamilySearch, https://familysearch.org).

90 ARPEZ. Civiles C-37-12 [1828-1829], C-39-1 [1829-1830], C-44-2 [1830-1832], C-206-6 $[1850]$. 
dichas ocasiones como objetos irresistibles ante sus propios portadores y ante aquéllos con quienes se interactuaba.

\section{A MOdo DE CONCLUSIÓN}

Se realizó una aproximación a la cultura material en la parroquia rural Inmaculada Concepción de La Cañada, Provincia de Maracaibo (Venezuela), en los años 1804-1860 al nivel de los objetos domésticos. La metodología utilizada permitió, en primer lugar, sistematizar la información disponible a partir de los usos y las funciones que posibilitaban las características materiales de dichos objetos, y caracterizar cuantitativamente, mediante un Índice de Nivel de Vida (INV), el grado de bienestar material del que habrían disfrutado los habitantes de la parroquia que poseían algún bien de fortuna. Los valores — por lo general, bajos — del INV indicaron que el grado de bienestar material de las familias representadas en el corpus documental habría sido bastante bajo. Todos los componentes de este indicador presentaron valores medios bajos, lo cual reflejaría la poca variedad de objetos domésticos de las diferentes categorías presentes en las viviendas de la parroquia en el período en cuestión. Es de pensar que tanto el nivel de bienestar material como la variedad de objetos presentes en las viviendas de las familias que no poseían bienes de fortuna hayan sido aún menores.

La concepción de los objetos domésticos como entidades que ejercen agencia material permitió aproximarse a la manera en que éstos habrían contribuido a producir y reproducir las relaciones sociales, las prácticas sociales y las identidades de los agentes sociales en la parroquia. Los objetos considerados en esta investigación como de primera necesidad y de confort habrían sido fijadores de estándares, objetos de relativo bajo perfil que ayudarían a tejer la fábrica invisible de lo "normal" y de lo "natural" en la parroquia La Cañada, afirmando estándares compartidos de conocimiento y comportamiento. Con base en el tipo de objetos de primera necesidad y de confort presentes en las viviendas de la parroquia se realizaron inferencias acerca de ciertas prácticas de los agentes sociales, tales como prácticas culinarias y prácticas asociadas a la organización del espacio doméstico, y acerca del posible papel que jugarían dichos objetos como fijadores de estándares en la afirmación o reafirmación de jerarquías sociales, de género o generacionales.

El estudio de la frecuencia de aparición en las viviendas de la parroquia de objetos considerados como de refinamiento y como objetos suntuarios permitió también realizar inferencias acerca de la agencia material de estos tipos de objetos. Así, se planteó que objetos de refinamiento como cuadros y esculturas de temas religiosos, objetos de mesa como cubiertos de plata, objetos de higiene personal y objetos utilizados en las prácticas de lectura y escritura presentes en algunas de las viviendas de la parroquia, habrían actuado 
materialmente como tecnologías de encantamiento, al incorporar cualidades estéticas o tecnológicas y pistas materiales que podían evocar un efecto específico en quienes interactuaban con ellos. Las familias de la parroquia se habrían rodeado de este tipo de objetos buscando quizás demostrar distinción o elegancia en sus prácticas y sus maneras sociales.

Por otra parte, se propuso que objetos suntuarios que habrían actuado como objetos irresistibles, objetos intrínsecamente deseables que podían ser exhibidos y portados por sus propietarios y que habrían evocado los valores de los grupos sociales de la parroquia a través de su confección, sus materiales de elaboración y/o su simbolismo, habrían sido también un elemento importante en la distinción social en la parroquia. Las familias de la parroquia se habrían esforzado en poseer y exhibir dichos objetos suntuarios como un medio para afirmar materialmente sus pretensiones de prestigio y crédito social, asociadas quizás a la pertenencia al grupo étnico tradicionalmente dominante en la parroquia. Se argumentó que la posesión de estos objetos suntuarios pudo responder también a una estrategia de materialización del ahorro en objetos de valor que pudieran haber sido fácilmente convertibles en dinero en efectivo, y que habrían ayudado a hacer frente a deudas o a salir de apuros económicos en momentos de falta de liquidez.

En general, los objetos domésticos aquí discutidos tendrían ciertos usos y funciones posibilitadas por sus características materiales, mientras que al incorporar en su diseño una lógica de respuestas anticipadas, habrían actuado sobre los agentes sociales de la parroquia comunicando significados y narrativas, memorias y formas de clasificar y categorizar el mundo. Se espera que a medida que se realicen estudios similares para otras sociedades hispanoamericanas para el período en cuestión recurriendo al marco teóricometodológico aquí utilizado, puedan establecerse tendencias de alcance más general sobre los niveles de bienestar material existentes en dichas sociedades en función del contexto sociocultural, y sobre la forma en que los objetos domésticos pudieron contribuir mediante su agencia material a producir, reproducir y transformar las relaciones sociales y las prácticas e identidades de los agentes sociales.

\section{FuENTES DOCUMENTALES}

\section{Fuentes primarias manuscritas}

Archivo del Registro Principal del Estado Zulia (ARPEZ)

Civiles. C-2-14 [1804], C-4-1 [1820], C-6-14 [1815], C-12-9 [1820], C-37-10 [18271828], C-37-12 [1828-1829], C-39-1 [1829-1830]. C-44-2 [1830-1832], C-862 [1832], C-105-9 [1838], C-123-2 [1840], C-132-15 [1841], C-197-10 [1848], C-206-6 [1850], C-206-18 [1851], C-255-2 [1846], C-255-16 [1857], C-255-5 [1860]. 
Nota: La sección "Civiles" del Registro Principal del Estado Zulia ha sido trasladada por las autoridades competentes al Acervo Histórico del Estado Zulia, ubicado en la ciudad de Maracaibo.

Archivo Parroquial de La Inmaculada Concepción de La Cañada, Estado Zulia (APIC)

\section{Libros de bautismos}

Tomo I de Bautismos. Volumen de Recopilación de los Cinco Primeros Libros de Bautismos de las clases Blancas, Pardas y Esclavos (años 1785-1839).

\section{Libros de matrimonios}

Libro Primigenio de Matrimonios de Vecinos Españoles, conteniendo Matrimonios desde 1785 hasta 1811 y desde 1847 hasta 1848 .

"Libro parroquial donde se asientan las partidas de casamiento de gente blanca perteneciente a la parroquia de la Inmaculada Concepción de La Cañada hecho por su propio párroco Pbro. Lorenzo Romero, comienza a correr el veinte y uno de abril del año de 1825 ".

Tomo 4 de matrimonios, 1841-1860.

\section{Archivos de la parroquia El Sagrario y San Juan de Dios de Maracaibo}

Libros de bautismos, matrimonios y defunciones de los siglos XVIII y xIx. Consultados en: "Venezuela, registros parroquiales y diocesanos, 1577-1995." Database with images. FamilySearch. http://FamilySearch.org: accessed 2016. Parroquias Católicas, Venezuela (Catholic Church parishes, Venezuela).

\section{Fuentes primarias impresas}

Buchan, Jorge, Medicina doméstica, Imprenta Real, Madrid, 1785. https://archive.org/ details/b28769491/page/n5

Carreño, Manuel Antonio, Manual de urbanidad y buenas costumbres para uso de la juventud de ambos sexos en el cual se encuentran las principales reglas de civilidad y etiqueta que deben observarse en las diversas situaciones sociales, [Primera edición 1853], Editorial CEC, S. A. Los libros de El Nacional, Caracas, 2005.

Rivas, José María, Costumbres zulianas. Imprenta Americana, Maracaibo, 1910 [Primera edición 1883]. https://archive.org/details/costumbreszulian00riva/ page/92

\section{REFERENCIAS}

Almenar Fernández, Luis, "Los inventarios post mortem de la Valencia medieval. Una fuente para el estudio del consumo doméstico y los niveles de vida", Anuario de Estudios Medievales, vol. 47, núm. 2, 2017, pp. 533-566.

DOI: https://doi.org/10.3989/aem.2017.47.2.02 
Alzate Echeverri, Adriana María, "Los manuales de salud en la Nueva Granada (17601810) ¿El remedio al pie de la letra?”, Fronteras de la Historia, núm. 10, 2005, pp. 209-252. DOI: https://doi.org/10.22380/20274688.587

Amodio, Emanuele, "El pan nuestro de cada día. Comercio de harina de trigo y consumo de pan en Caracas durante el siglo XviI", Nuestro Sur, año 10, núm. 15, 2019, pp. 83-110. http://www.cnh.gob.ve/images/NuestroSur15.pdf

Bartolomé Bartolomé, Juan, "Patrimonios, condiciones de vida y consumo. La burguesía administrativa y las profesiones liberales en la ciudad de León. 17001850", en García Fernández, Máximo (dir.), Cultura material y vida cotidiana moderna: escenarios, Síles ediciones S. L., Madrid, 2013, pp. 73-89.

Bauer, Arnold J., Goods, Power, History. Latin America's Material Culture, Cambridge University Press, Cambridge, 2001.

Baulant, Micheline, "L'áppréciation du niveau de vie. Un problème, une solution", Historie \& Mesure, vol. 4, nos. 3-4, 1989, pp. 267-302.

DOI : https://doi.org/10.3406/hism.1989.1361

Baulant, Micheline, “Ascétique ou douillette ? L'existence des ecclésiastiques de Brie aux XVIIe et XVIIIe siècles". Annales de Bretagne et des pays de l'Ouest, vol. 94, no 4, 1987, pp. 475-486. DOI : https://doi.org/10.3406/abpo.1987.3271

Benzecry, Claudio E. y Domínguez Rubio, Fernando, The cultural life of objects, UC San Diego Previously Published Works. eScholarship.org, 2018. https://escholarship.org/uc/item/3px8m88x

Bermúdez Briñez, Nilda, "Condiciones de vida de una ciudad-puerto del Occidente de Venezuela (1830-1860) "Revista LIDER, vol. 14, año 10, 2005, pp. 43-59. http://ceder.ulagos.cl/lider/images/numeros/14/04.\%20Condiciones $\% 20 \mathrm{de} \% 20$ vida $\% 20 \mathrm{de} \% 20$ una $\% 20$ ciudad $\% 20$ puerto.pdf

Bermúdez Briñez, Nilda, Vivir en Maracaibo en el siglo XIX, Colección V Centenario del Lago de Maracaibo, Acervo Histórico del Estado Zulia, Maracaibo, 2001.

Bouchard, Dominique, "La culture matérielle des canadiens au XviIe siècle: analyse du niveau de vie des artisans du fer", Revue d'histoire de l'Amérique française, vol. 47, no. 4, 1994, pp. 479-498.

DOI: https://doi.org/10.7202/305276ar

Braudel, Fernand, The structures of Everyday Life. Civilization \& Capitalism 15th-18th Century, vol. 1, Harper \& Row, Publishers, New York, 1981.

Cardozo Galué, Germán, Maracaibo y su región histórica. El circuito agroexportador 1830-1860, Colección Centenario de LUZ, Editorial de La Universidad del Zulia. Maracaibo, 1991.

Catálogo del Patrimonio Cultural Venezolano 2004-2008. Estado Zulia. Municipio La Cañada de Urdaneta, Instituto del Patrimonio Cultural, República Bolivariana de Venezuela, Caracas, 2007. https://issuu.com/mvzulia/docs/canadadeurdaneta

Catálogo del Patrimonio Cultural Venezolano. Municipio La Cañada de Urdaneta. Instituto del Patrimonio Cultural. Caracas, Pre-inventario del patrimonio cultural del estado Zulia - Bienes inmuebles y muebles, Convenio IPCCRU-LUZ, Instituto de Investigaciones de la Facultad de Arquitectura de la Universidad del Zulia, Maracaibo, 1996. 
Correa, Carolina y Wibaux, Matías, "Sabores de la pampa. Dieta y hábitos de consumo en la frontera bonaerense", en Mayo, Carlos A. (ed.), Vivir en la frontera. La Casa, la dieta, la pulpería, la escuela (1770-1870), Historias Americanas, Editorial Biblos, Buenos Aires, 2000.

Diccionario de la lengua castellana por la Academia española, 8a. Edición, Imprenta Nacional, Madrid, 1837. https://hdl.handle.net/2027/nyp.33433000337190

Duarte, Carlos F. Mobiliario y decoración interior durante el periodo Hispánico Venezolano. Armitano Editores, Caracas, 1995.

Elías, Norbert, El proceso de la civilización. Investigaciones sociogenéticas y psicogenéticas, Fondo de Cultura Económica, Madrid, 1987.

Gell, Alfred, Art and Agency. An Anthropological Theory, Clarendon Press, Oxford, 1998.

Hernández López, Carmen, "Trastillos de casa pobre. Homenaje de casa decente”. Una visión diferenciada de las casas, ajuares y espacios domésticos desde el mundo rural manchego a finales del Antiguo Régimen", Tiempos Modernos, vol. 32, núm. 1, 2016, pp. 457-477.

http://tiemposmodernos.org/tm3/index.php/tm/article/view/1295/654

Hernández López, Carmen, "Pautas de consumo doméstico en las tierras de la Mancha oriental (1620-1850)", Ensayos. Revista de la Facultad de Educación de Albacete, núm. 27, 2012, pp. 159-187.

https://revista.uclm.es/index.php/ensayos/ issue/view/23

Hersch Martínez, Paul, “Tres textos de medicina en México: Velasco, Barajas y López Tilgham”, Boletín Mexicano de Historia y Filosofía de la Medicina, vol. 7, núm. 1, 2004, pp. 11-18. https://www.medigraphic.com/pdfs/bmhfm/hf-2004/hf041c.pdf

Hodder, Ian, Studies in Human-Thing Entanglement, Edición de autor, 2016. https:// www.researchgate.net/profile/Ian_Hodder/publication/297459200_Studies_ in_Human-Thing_Entanglement/links/5715bd7a08ae1a840265048f.pdf

Moreno Claverías, Belén, "Lugar de residencia y pautas de consumo. El Penedés y Barcelona, 1770-1790”, Revista de Historia Industrial, núm. 31, año XV, 2006, pp. 139-165. DOI: https://doi.org/10.1344/rhi.v15i31.19664

Moreno Claverías, Belén, "Pautas de consumo y diferenciacion social en el Penedés a fines del siglo XVII. Una propuesta metodológica a partir de inventarios sin valoraciones monetarias", Revista de Historia Económica, año XXI, núm. Extraordinario, 2003, pp. 207-245.

DOI: https://doi.org/10.1017/S021261090001082X

Moreyra, Cecilia Edith, "La alcoba, el lecho, lo cotidiano. Cultura material de un espacio doméstico. Córdoba (Argentina), siglos XVIII y XIX”. Páginas, año 10, núm. 24, 2018, pp. 95-117.

DOI: https://doi.org/10.35305/rp.v10i24.311

"Cocinar y comer en la Córdoba (Argentina) del siglo XIX. Una lectura de la cultura material doméstica", Revista de Estudios Latinoamericanos de la Universidad pablo de Olavide de Sevilla, núm. 6, julio-diciembre, Nueva Época, 2017a, pp. 262-294. https://rio.upo.es/xmlui/handle/10433/5277 
, "Cultura material e higiene cotidiana en la Córdoba del Ochocientos", Anuario de Estudios Americanos, vol. 74, núm. 1, 2017b, pp. 211-234.

DOI: https://doi.org/10.3989/aeamer.2017.1.08

_ - "Vida cotidiana y entorno material. El mobiliario doméstico en la ciudad de Córdoba a fines del siglo XVIII”, Historia Crítica, núm. 38, 2009, pp. 122-144. DOI: https://doi.org/10.7440/histcrit38.2009.07

Navarrete, Rodrigo, "Torrentes domesticados. La arqueología del agua en la Caracas colonial”, Nuestro Sur, año 10, núm. 15, 2019, pp. 37-58. http://www.cnh.gob.ve/images/ NuestroSur15.pdf

Overholtzer, Lisa y Robin, Cynthia, "The Materiality of Everyday Life", Archaeologial papers of the American Anthropological Association, vol. 26, 2015, pp. 1-9. DOI: https://doi.org/10.1111/apaa.12057

Pellicer, Luis Felipe, La vivencia del honor en la provincia de Venezuela 1774-1809, Fundación Polar, Caracas, 1996.

Pirela Torres, Alexis, Casas de Maracaibo 1674-1930, Universidad del Zulia, Facultad de Arquitectura y Diseño, Maracaibo, 2007.

Ransom, Tailer Geoffrey, "Artifacts, others, and temporality: an enactive and phenomenological approach to material agency", tesis de doctorado en Filosofía, University of Memphis, Memphis, Estados Unidos, 2019.

Randazzo Ruiz, Marcela, "La honorabilidad en la apariencia: teatralidades cotidianas y escenificación de la blancura en el Virreinato de la Nueva Granada (17501806)", Revista Cambios y Permanencias, núm. 8, 2017, pp. 427-454.

https://revistas.uis.edu.co/index.php/ revistacyp/article/view/6967/7214

Reyes Cárdenas, Catalina, Aspectos de vida social y cotidiana en Medellín, 1890-1930, Colcultura, Instituto Colombiano de Cultura, Bogotá, 1996.

Rincón Rubio, Luis, "El paisaje del parentesco en la parroquia Inmaculada Concepción de La Cañada (Provincia de Maracaibo) a fines del siglo XVII y principios del siglo xix, Diálogos Revista Electrónica de Historia, vol. 20, núm. 1, enero-junio 2019, 2019a, pp. 94-129. DOI: https://doi.org/10.15517/DRE.V20I1.34266 , "Cultura material y vivienda doméstica en una parroquia rural de la Provincia de Maracaibo en la primera mitad del siglo XIx: La Inmaculada Concepción de La Cañada”. Procesos Históricos, vol. 26, núm. 13, 2019b, pp. 106-146.

http://erevistas.saber.ula.ve/index.php/procesoshistoricos/article/view/9811

__ La Cañada de Urdaneta. Documentos para su historia (1836-1936), Biblioteca Temas de Historia del Zulia, Acervo Histórico del Estado Zulia, Maracaibo, 2011.

, "La economía en la región histórica zuliana: caso la Cañada de Urdaneta (1834-1926)", Procesos Históricos, año XI, núm. 22, 2012, pp- 95-137.

, Mujer y honor en Maracaibo a fines del siglo XIX (1880-1900), Colección Textos Universitarios, Ediciones del Vice Rectorado Académico, Universidad del Zulia, Maracaibo, 2010.

, "Orígenes y consolidación de una parroquia rural en la provincia de Maracaibo:

La Inmaculada Concepción de La Cañada, 1688-1834”, Procesos Históricos, año 6, núm. 12, 2007, pp. 2-55.

http://erevistas.saber.ula.ve/ index.php/procesoshistoricos/article/view/9567 
—_ La Inmaculada Concepción de La Cañada. Orígenes, estructura familiar y prácticas sociales (1688-1838), Tipografía Mundo, Maracaibo, 2003.

Rivas P., Jorge F., El repertorio clásico en el mobiliario venezolano siglos XVIII y XIX, Colección Patricia Phelps de Cisneros, Cuaderno 9, Fundación Cisneros, Caracas, 2007.

Robb, John, "What Do Things Want? Object Design as a Middle Range Theory of Material Culture", Archaeological papers of the American Anthropological Association, vol. 26, 2015, pp. 166-180.

DOI: https://doi.org/10.1111/apaa.12069

, "Beyond Agency". World Archaeology, vol. 42, no. 4, 2010, pp. 493-520.

DOI: https://doi.org/10.1080/00438243.2010.520856

Sánz de la Higuera, Francisco José, “Aproximación a la mesa de los burgaleses. Cuberterías y platos en el setecientos", en García Fernández, Máximo (dir.), Cultura material y vida cotidiana moderna: escenarios, Síles ediciones S. L., Madrid, 2013, pp. 183-195.

Sobrado Correa, Hortensio, "Los inventarios post mortem como fuente privilegiada para el estudio de la historia de la cultura material en la edad moderna", Hispania, vol. LXIII-3, núm. 215, 2003, pp. 825-861.

DOI: https://doi.org/10.3989/hispania. 2003.v63.i215.207 